\title{
Modelling the impact of climate change on harbour operability: The Barcelona port case study
}

\author{
J.P. Sierra ${ }^{a, b}$, A. Genius ${ }^{a}$, P. Lionello ${ }^{c, d}$, M. Mestres ${ }^{a, b}$, C. Mösso ${ }^{a, b}, \&$ L. Marzo ${ }^{c}$ \\ aLaboratori d'Enginyeria Marítima, Universitat Politècnica de Catalunya, BARCELONATECH, \\ Jordi Girona 1-3, Mòdul D1, Campus Nord, 08034 Barcelona, Catalonia, Spain \\ ${ }^{b}$ Centre Internacional d'Investigació dels Recursos Costaners (CIIRC), Jordi Girona 1-3, Mòdul \\ D1, Campus Nord, 08034 Barcelona, Catalonia, Spain \\ 'Dipartimento Scienze e Tecnologie Biologiche e Ambientali (DiSTeBA), University of Salento, \\ Lecce, Italy \\ ${ }^{\mathrm{d} E u r o M e d i t e r r a n e a n}$ Center on Climate Change (CMCC), Lecce, Italy \\ e-mail:Joan.pau.sierra@upc.edu
}

\begin{abstract}
Harbours are essential infrastructures for economic activity that are susceptible to impacts from climate change driven processes, like sea level rise (SLR), or alterations in wave patterns. In this paper, the impact of climate change on wave agitation in ports (oscillations due to wind waves) and, therefore, on port operability is analyzed. This is carried out through a numerical model suite, considering the RCP8.5 scenario to project changes in wave fields, and three values of SLR. The study is particularized for the port of Barcelona (NW Mediterranean), but the used methodology can be applied to other harbours. Results suggest that changes due only to waves will be minimal and with a general trend to slightly decrease wave agitation. On the contrary, the effect of SLR and the associated increase of water depth will favor the penetration of waves within the harbour, leading to a certain reduction of port operability, the magnitude of which will depend on the SLR value. However, the complexity of wave patterns within the harbours, due to multiple reflections of waves on port structures, implies that the reduction of operability strongly varies according to the position and orientation of the berthing zones inside the harbour.
\end{abstract}

\section{Introduction}

Climate change has become a major focus of attention because of its potential hazards and impacts on the environment, particularly in vulnerable systems like coasts (Sánchez-Arcilla et al., 2011). In coastal areas, vulnerability assessments have focused mainly on the sea level rise (SLR) and its impact on coastal communities (Nicholls et al., 2011), addressing its effects on beaches (e.g. Revell et al., 2011; Sánchez-Arcilla et al., 2011; Monioudi et al., 2016), coastal defense structures (e.g. Isobe, 2013; Lee et al., 2013; Burcharth et al., 2014), coastal 
ecosystems (e.g. Reynolds et al., 2012; Kane et al., 2015), or the flooding of urban areas (e.g. Hallegatte et al., 2011; Paudel et al., 2015).

In addition, SLR is not the only physical process of concern to coastal communities being affected by climate change. Potential changes in wind and atmospheric pressure distributions will modify the wave field pattern (Weisse and von Storch, 2010), which is another essential coastal driver. Indeed, changes in ocean wave climate have been reported in several studies (e.g. Lionello et al., 2008, 2016; Wang et al., 2009; Hemer et al., 2010, 2013a, 2013b; Hemer and Trenham, 2016). The potential impacts of the modification of wind wave properties due to climate change on the coast and nearshore have attracted increased attention in recent years (Zacharioudaki and Reeve, 2011; Adams et al., 2011; Barnard et al., 2014; Sierra and CasasPrat, 2014; Casas-Prat et al., 2016).

Since seaports are located on the coast or in estuaries, they are susceptible of being affected by both SLR and wave storms. Harbour activities are strongly dependent on wave features, especially in relation with the safe entrance and exit of ships, but also for the regular port operations (Rusu and Guedes Soares, 2013). For these, the wave parameters inside the basin must not exceed certain thresholds, which depend on the type of operation (mooring, loading or unloading) and cargo involved (López et al., 2015). Moreover, as port infrastructures have often been designed for present climatic conditions, they will likely be affected by climate change (Sánchez-Arcilla et al., 2016). The increase in mean sea level or changes in the wave climate will condition essential aspects of harbour infrastructure and operations, modifying their risk levels and economic productivity. This represents one of the main climatic risks in coastal zones, since the contribution of ports to the economic activity in the coastal fringe and their hinterland is significant (Becker et al., 2012; PIANC, 2012; Sánchez-Arcilla et al., 2016).

SLR will increase the water depth around and inside the harbour, modifying wave propagation patterns that can in turn produce other impacts on ports, affecting processes such as wave agitation (oscillations due to wind waves within the port), siltation or structure stability (Sierra and Casas-Prat, 2014). On the other hand, changes in wave height will modify the amount of energy entering the harbours, while changes in wave period or direction will modify propagation processes such as shoaling, refraction and diffraction, thus likely inducing changes in sediment transport patterns (potentially generating siltation) or wave penetration into harbours (Sierra and Casas-Prat, 2014), and affecting port operability. All these impacts can be either positive or negative, i.e. they can improve or worsen the operability of ports.

Current port management protocols are not yet considering the effects of these potential impacts on their own operations (Becker et al., 2012), and the studies addressing the impacts of climate change on harbours (e.g. Hanson et al., 2011; Asariotis and Benamara, 2012; Messner et al., 2013; McEvoy et al., 2013; Chhetri et al., 2013; Sánchez-Arcilla et al., 2016) are few compared with the numerous assessments of such impacts on coastal areas (see previous references). Of the former, some focus on the climate change effects on a single process, such as wave agitation in ports (Casas-Prat and Sierra, 2010, 2012; Sierra et al., 2015), port breakwater overtopping (Sierra et al., 2016) or port breakwater stability (Takagi et al., 2011; Mase et al., 
2013; Suh et al., 2013), while others analyze the whole vulnerability of ports to climate change and propose adaptation measures ( $\mathrm{Ng}$ et al., 2013; Nursey-Bray et al., 2013; Becker et al., 2013, 2015; Chhetri et al., 2015).

The aim of this paper is to assess the modifications in port operability times associated to SLR and to wave pattern variations induced by climate change. The study is conducted using a series of numerical models to analyze changes in wave agitation (wind wave heights) within the Barcelona port (NW Mediterranean) produced by the aforementioned climatic drivers. The paper analyzes only inoperability due to wind waves, ignoring other factors that could affect harbour operations (wind, currents), which are out of the scope of this work. Although the study is particularized in a single port, the methodology here described is applicable to any harbour worldwide. Section 2 describes the models and data used. Section 3 presents and discusses the results of the simulations for the different scenarios considered, underlining the implications for port operability. Finally, Section 4 summarizes the main conclusions of this study.

\section{Data and methods}

\subsection{Study area}

The Port of Barcelona is located in the center of the Catalan coast $\left(41^{\circ} 21^{\prime} \mathrm{N}, 2^{\circ} 10^{\prime} \mathrm{E}\right)$ in the northwest Mediterranean Sea, as illustrated in Fig. 1. In 2014 it was considered the third European port in terms of productivity with a throughput of 45.3 millions of tons, 1.9 million TEU and almost 3.5 million passengers (BPA, 2015). The current port land area is over 1000 ha with $22.3 \mathrm{~km}$ berthing length and a depth of up to $16 \mathrm{~m}$. The study has considered 21 zones representing groups of docks with the same type of activity and similar features. In these zones, only commercial berths with a berthing line longer than $35 \mathrm{~m}$ are considered. In Table 1, this classification is presented and in Fig. 2 their position inside the port is shown.

The NW Mediterranean is a microtidal environment, with an average tidal amplitude of about 25 $\mathrm{cm}$. The meteo-oceanographic characteristics of this area are strongly subordinated to its semienclosed character and complexity: presence of orographic barriers like the Pyrenees, veering winds, shadow effects caused by islands like the Balearic, and irregular bathymetry with submarine canyons close to the coast. This determines the spatial distribution of winds and, therefore, of the wave field, leading to a large seasonal variability (Lionello et al., 2002, Campins et al., 2011). In particular, the Catalan coast is characterized for having weak-to-medium winds with occasional strong events, resulting in mild wave conditions with sporadic energetic wave storms. The significant wave height in the region is smaller than $1 \mathrm{~m}$ on average, but it can reach up to 6-7.5 m during extreme events (Sánchez-Arcilla et al., 2008). Waves from the $E$ and the $S$ are the most frequent, and those from the $E$ have the largest heights because strong winds and a long fetch concur along this direction (Sánchez-Arcilla et al., 2008; Casas-Prat et al., 2014). 


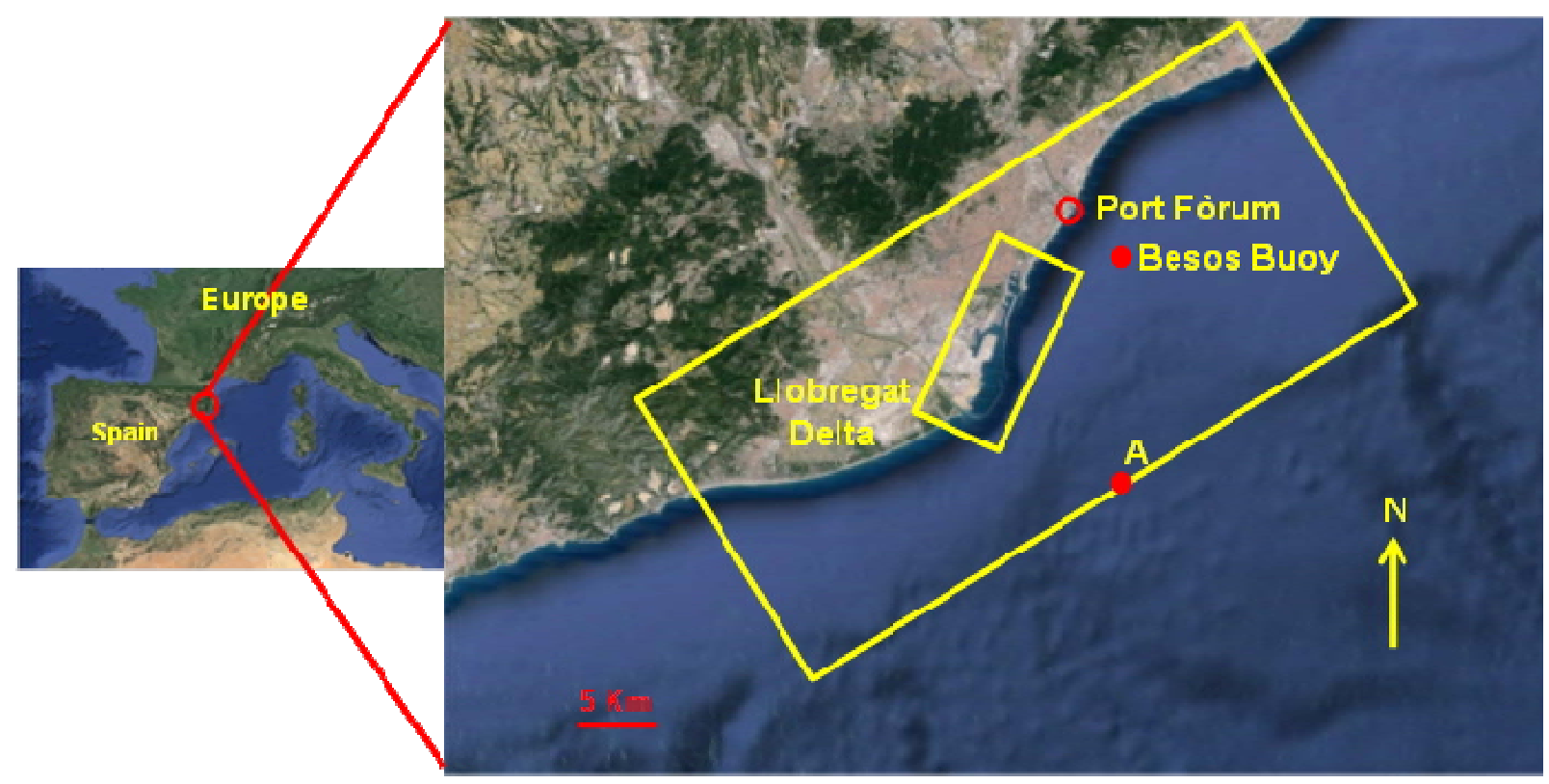

Fig. 1 Location of the port and other points of interest. The rectangles correspond to the two model grids used. "A" indicates the position of the closest grid point from the Mediterranean model.

\begin{tabular}{|c|c|c|c|c|c|}
\hline Zone & Length $\mathbf{( m )}$ & $\begin{array}{c}\text { Average } \\
\text { depth } \mathbf{( m )}\end{array}$ & Use & \multicolumn{2}{|c|}{$\begin{array}{c}\text { Threshold wave } \\
\text { heights }\end{array}$} \\
\cline { 5 - 6 } & & & & $\mathbf{H}_{\mathbf{s T}} \mathbf{( m )}$ & $\mathbf{H}_{\text {sL }} \mathbf{( m )}$ \\
\hline 1 & 480 & 16.0 & General \& bulk cargo & 0.8 & 1.0 \\
\hline 2 & 500 & 12.0 & General cargo & 0.8 & 1.0 \\
\hline 3 & 1368 & 11.9 & Cruises & 0.3 & 0.5 \\
\hline 4 & 310 & 8.6 & Cruises \& yachts & 0.3 & 0.5 \\
\hline 5 & 634 & 7.5 & Ferries & 0.3 & 0.5 \\
\hline 6 & 160 & 9.5 & Ferries & 0.3 & 0.5 \\
\hline 7 & 1388 & 9.8 & Ferries & 0.3 & 0.5 \\
\hline 8 & 374 & 8.7 & General cargo & 0.8 & 1.0 \\
\hline 9 & 850 & 11.2 & Ferries & 0.3 & 0.5 \\
\hline 10 & 241 & 10.8 & Bulk cargo & 0.8 & 1.0 \\
\hline 11 & 419 & 12.0 & Bulk cargo & 0.8 & 1.0 \\
\hline 12 & 198 & 12.0 & Bulk cargo & 0.8 & 1.0 \\
\hline 13 & 1362 & 14.0 & Containers & 0.3 & 0.5 \\
\hline 14 & 350 & 12.0 & Oil products & 1.0 & 1.5 \\
\hline 15 & 460 & 12.0 & General cargo & 0.8 & 1.0 \\
\hline 16 & 348 & 8.0 & Ro-Ro & 0.3 & 0.5 \\
\hline 17 & 1096 & 11.0 & Containers & 0.3 & 0.5 \\
\hline 18 & 258 & 8.0 & Ro-Ro & 0.3 & 0.5 \\
\hline 19 & 997 & 9.3 & Ro-Ro & 0.3 & 0.5 \\
\hline 20 & 1190 & 12.0 & LNG \& LPG & 0.8 & 1.2 \\
\hline 21 & 1500 & 11.7 & Containers & 0.3 & 0.5 \\
\hline
\end{tabular}


Table 1 Berthing zones considered, with their features: length, average depth, use and threshold wave heights (Puertos del Estado, 2000) that allow operations depending on whether significant wave heights are longitudinal $\left(\mathbf{H}_{\mathrm{sL}}\right)$ or transversal to the dock $\left(\mathbf{H}_{\mathrm{ST}}\right)$.

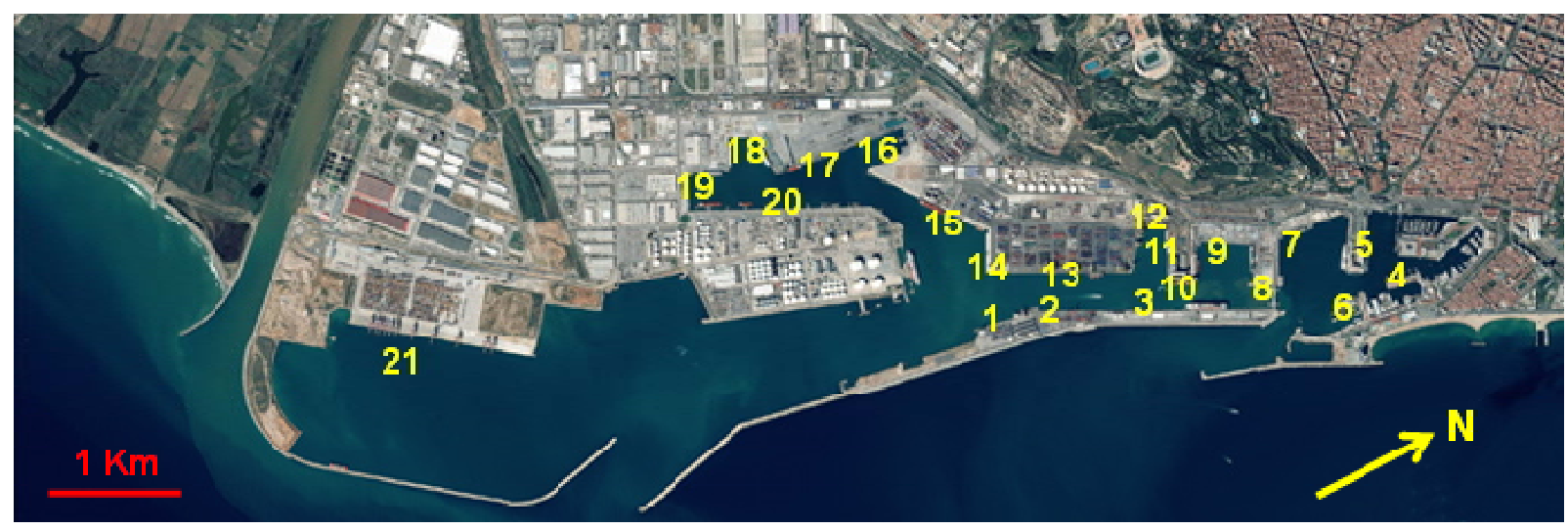

Fig. 2 Location of the 21 berthing zones considered in this study.

\subsection{Wave and SLR data}

In order to analyze the potential impacts of climate change on harbours, projections of wave climate and SLR are necessary. Different methods have been used to obtain projections of future wave climate, such as extrapolating trends in historical data, for instance (e.g. Casas-Prat and Sierra, 2010, 2012; Wang et al., 2012). However, the results of this approach strongly depend on trend assumptions and cannot adequately account for climate change.

There is thus a need for further analyses. In this context, global circulation models (GCMs) allow to estimate changes associated to future climate scenarios, but they do not simulate ocean waves, and the resolution of the wind fields they provide is too coarse to force regional wave models (Perez et al., 2015). To project future wave conditions considering the climate scenarios there are basically two different approaches: dynamical downscaling (e.g. Casas-Prat and Sierra, 2013; Hemer et al., 2013a; Laugel et al., 2014; Hemer and Trenham, 2016) which uses wave models forced by nested GCMs and regional circulation models (RCMs), and statistical downscaling (e.g. Casas-Prat et al., 2014; Laugel et al., 2014; Wang et al., 2014; MartínezAsensio et al., 2016), which is based on building an empirical relationship between atmospheric variables and wave climate parameters.

Several authors have used dynamical downscaling to perform regional studies in different European areas, like Lionello et al. (2008) in the Mediterranean Sea, or Grabemann et al. (2015) in the North Sea. In this paper, the wave climate data used has also been computed using dynamically downscaled wind fields produced by the Euro-Mediterranean Center on Climate Change (CCMC). The regional climate simulation has been based on the RCP8.5 scenario from the 5th Assessment Report (AR5) of IPCC (Church et al., 2013). Waves have been calculated using the numerical model WAM (The WAMDI Group, 1988) whose domain covers the whole 
Mediterranean Sea with a resolution of $0.25^{\circ} \times 0.25^{\circ}$. Time series of significant wave height $\left(\mathrm{H}_{\mathrm{s}}\right)$, peak period $\left(T_{p}\right)$ and wave direction, every $3 \mathrm{~h}$ for the time interval 1950-2100 have been extracted at the closest point to Barcelona harbour. This approach is different from that followed in Sierra et al. (2015), where the scenario used was A1B from the 4th Assessment Report of IPCC (2007) and where wave data were obtained from 5 combinations of RCM/GCM atmospheric data, allowing to analyze the variability between models. Another substantial difference is that this previous study did not take into account the SLR, while here the potential influence of SLR in wave agitation in the port is considered. In addition, in this study the directional resolution is larger (sectors of $22.5^{\circ}$ instead of $45^{\circ}$ ). Finally, in Sierra et al. (2015) only the average values of wave agitation in the whole port were considered, while here a more indepth study is carried out, analyzing berth to berth and assessing inoperability times.

The wave parameters given by the model for the period 1986-2005 are considered present conditions, while future conditions span the period 2081-2100. These periods have been selected because they coincide with those used by the IPCC in the AR5 (Church et al., 2013).

Regarding SLR, the AR5 of IPCC (Church et al., 2013) suggests that the global mean sea level in the period 2081-2100 will be between 0.26 and $0.82 \mathrm{~m}$ higher than during 1986-2005, with a maximum value of $0.98 \mathrm{~m}$ (for scenario RCP8.5) by 2100 with respect to this last period. Other recent studies project much higher mean SLRs for 2100: up to $1.86 \mathrm{~m}$ (Jevrejeva et al., 2012; Mori et al., 2013) or even up to $2 \mathrm{~m}$ (Rahmstorf, 2007). In addition, AR5 projections indicate that SLR in the Mediterranean Sea will be slightly lower than the global SLR average (up to $10 \%$ ). Taking this into account, three SLR scenarios are considered for the future conditions, giving rise to the four scenarios defined in this paper:

- Scenario 0: Present wave conditions (1986-2005) and bathymetry (base level).

- Scenario 1: Future wave conditions (2081-2100) and base level (SLR = $0 \mathrm{~m}$ )

- Scenario 2: Future wave conditions (2081-2100) and base level $+0.88 \mathrm{~m}$

- Scenario 3: Future wave conditions (2081-2100) and base level $+1.80 \mathrm{~m}$

Scenario 1 has been included to analyze the impacts due only to changes in the wave fields (without SLR). Scenario 2 corresponds to the maximum value for RCP8.5 (assuming a 10\% decrease with respect to the global averages) and Scenario 3 is a high-end scenario representative of very extreme SLR (2 $\mathrm{m}$ in the global average minus $10 \%)$, physically feasible although with a very low probability of occurrence ( $<5 \%$ by 2100 , Jevrejeva et al., 2014). Therefore, Scenario 2 is more plausible than Scenario 3, which is very unlikely and has been included in the study to account for the worst possible SLR conditions.

\subsection{Numerical modelling}

For the simulation of waves within the harbour, two numerical models and two different grids are used. Both domains and the corresponding bathymetries are shown in Figs. 1 and 3, respectively. The coarser grid, with a spatial resolution of $200 \times 200 \mathrm{~m}$, is used to propagate waves from offshore to the harbour vicinity with the SWAN model (Booij et al., 1999). The 
offshore wave conditions are given by the WAM wave projections described previously (Section 2.2) at the closest grid point (point A, Fig. 1), which are used as boundary conditions. In this area, shoaling and refraction are the most relevant wave transformation processes, and they are adequately reproduced by the SWAN code.
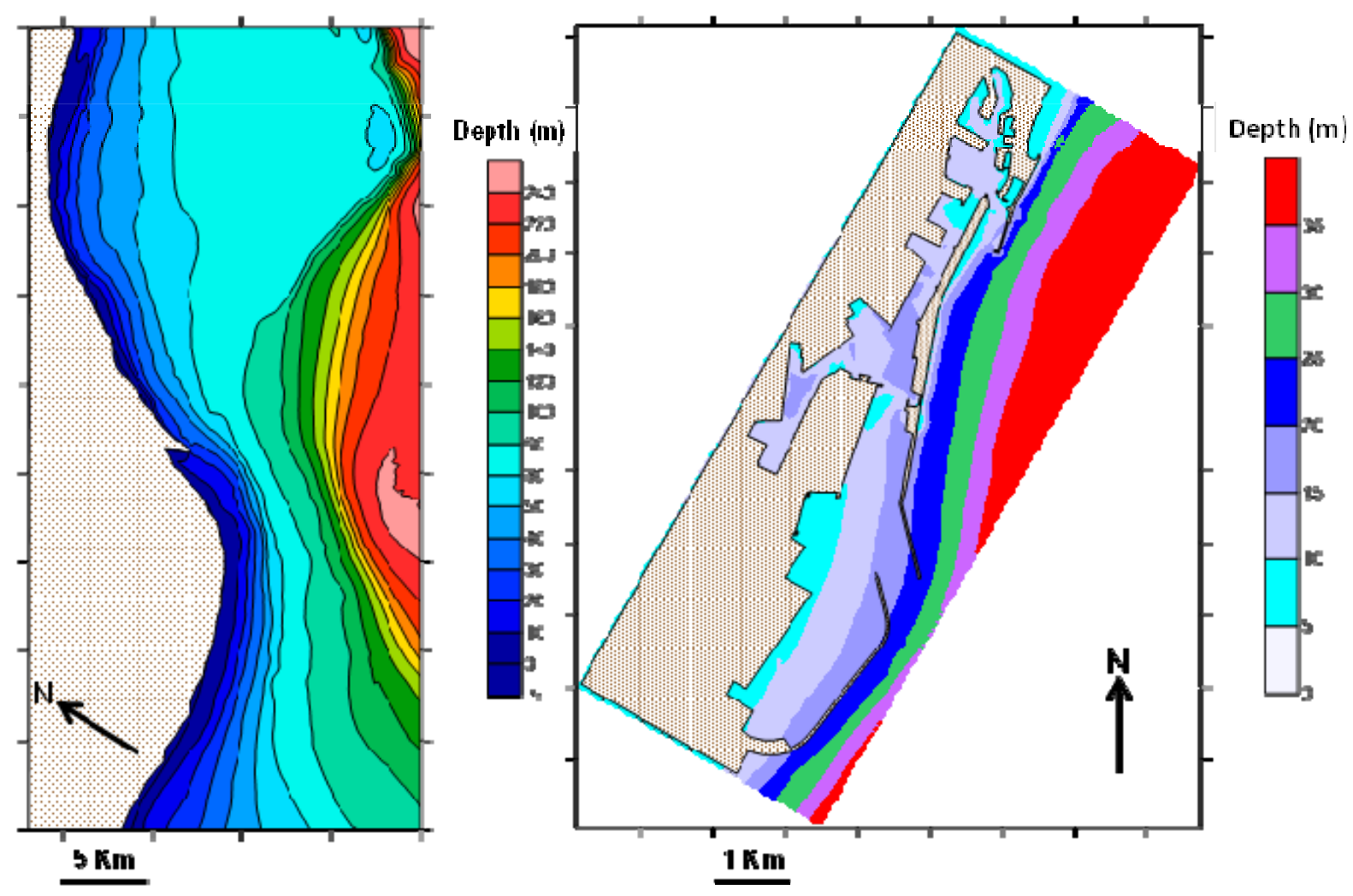

Fig. 3 Domains and bathymetries used in the simulations: Offshore to harbour entrance for SWAN model (left) and harbour for BT (right) model.

From the port entrance to each of the berths, reflection and diffraction also become important, so another type of model is necessary to simulate wave propagation inside the harbour. As pointed out by Rusu and Guedes Soares (2011), in the harbour areas the higher-resolution phase resolving models, based either on the mild slope equation or on the Boussinesq equations can give a realistic picture on the wave penetration inside the port. Therefore, for the finer grid a Boussinesq-type (BT) model with a spatial resolution of $5 \times 5 \mathrm{~m}$ is used. BT models have been widely used to simulate both wind-wave and long-wave propagation (e.g. Gierlevsen et al., 2001; Karambas and Koutitas, 2004; Woo and Liu, 2004; Kofoed-Hansen et al., 2005; Belloti, 2007; Belloti and Franco, 2011; Johnson and McComb, 2011; Thotagamuwage and Pattiaratchi, 2014 ) in port environments in which it is necessary to reproduce the aforementioned processes. In this paper, inharbour wave propagation is simulated with a BT model used in previous works (González-Marco et al., 2008; Casas-Prat and Sierra, 2010, 2012; Sierra et al., 2015), based on the weakly nonlinear equations of Abbott et al. (1978), and capable of reproducing shoaling, refraction, diffraction, reflection, bottom friction and non-linear interactions. A detailed description 
of the advantages, disadvantages and performance of this type of Boussinesq model can be found in Filippinni et al. (2015).

The modelling configuration could not be calibrated in the Barcelona port due to the lack of measurements inside the harbour, but it has been validated with wave data from the neighboring Port Fòrum (located $4.5 \mathrm{~km}$, northwards, see Fig. 1). These data were obtained from 3 wave sensors deployed within the port (see Fig. 4) during a 1-year campaign in 2012, and from the nearby Besòs wave buoy (see Fig. 1). The wave data recorded by the buoy were propagated towards the Port Fòrum following the same configuration than in the case of Barcelona port. The results are shown in Fig. 4 and Table 2, where the comparison between measured and modeled $\mathrm{H}_{\mathrm{s}}$ is presented. The model results show a mean absolute percentage error (MAPE) between $22 \%$ and $30 \%$, which can be considered reasonable taking into account the low value of $\mathrm{H}_{\mathrm{s}}$ at these inner points (average values between 0.10 and $0.22 \mathrm{~m}$ ) and the complexity of the processes involved. The number of measured data is different for each gauge because in some cases the device failed.
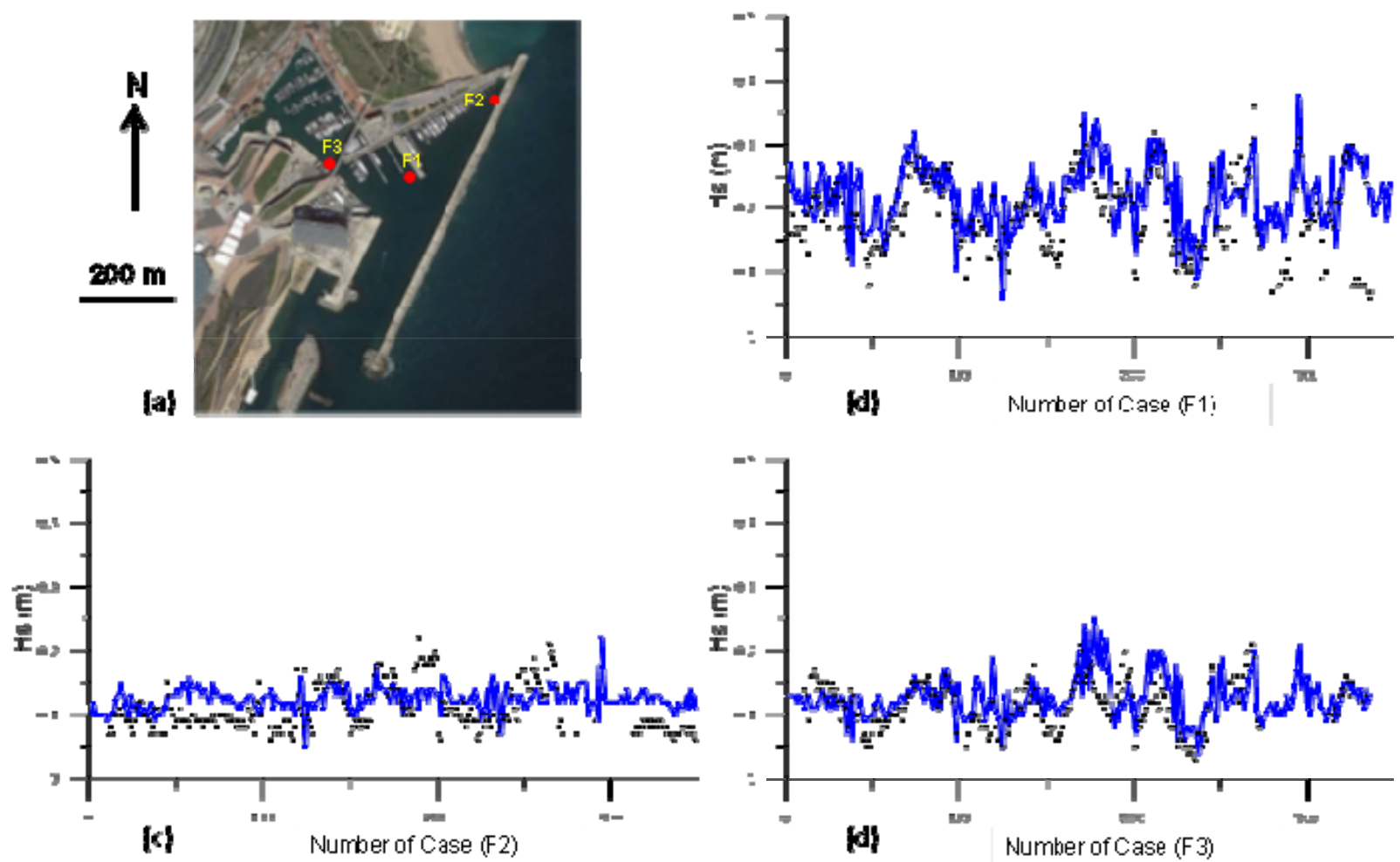

Fig. 4 Model validation at Port Fòrum. (a): Location of the three wave gauges within the port used for model validation. (b), (c) and (d): comparison between observations (dots) and model results (blue line). The x-axis shows the number of sequential cases used for validation. (For interpretation of the references to color in this figure legend, the reader is referred to the web version of this article). 


\begin{tabular}{|c|c|c|c|}
\hline $\begin{array}{c}\text { Wave } \\
\text { gauge }\end{array}$ & Number of data & Average $\mathbf{H}_{\mathbf{s}}(\mathrm{m})$ & MAPE $(\%)$ \\
\hline $\mathrm{F} 1$ & 309 & 0.219 & 24.4 \\
\hline $\mathrm{F} 2$ & 297 & 0.102 & 30.2 \\
\hline $\mathrm{F} 3$ & 322 & 0.128 & 22.1 \\
\hline
\end{tabular}

Table 2 Summary of results for the model validation within Port Forum.

To perform the simulations, instead of directly propagating the whole 20-year wave time series (with one data every $3 \mathrm{~h}$, totalizing 58,400 data), the wave regime has been characterized in order to limit the number of simulations to be carried out. The data have been grouped in sixteen $22.5^{\circ}$-directional sectors and five ranges of $\mathrm{H}_{\mathrm{s}}(0-1,1-2,2-3,3-4,>4$; in $\mathrm{m})$. Since there are only 8 wave directions (ENE, E, ESE, SE, SSE, S, SSW and SW) affecting the port because the other are directed offshore, each set of simulations entails 40 runs of the SWAN and BT models (8 directions $\times 5$ wave heights). Therefore, the total number of runs of each model is 160 (8 directions $\times 5 \mathrm{H}_{\mathrm{s}} \times 4$ scenarios), with one scenario corresponding to present conditions and the other three to future conditions with the different sea levels as described before.

After the grouping of the data, the frequency of occurrence of each group of $\mathrm{H}_{\mathrm{s}}$ and wave direction has been computed. Additionally, representative wave parameters have been assigned to each group. For each $\mathrm{H}_{\mathrm{s}}$ and direction, the central value of each bin has been considered, with the exception of the $>4 \mathrm{~m}$ group, for which a representative value of $5 \mathrm{~m}$ has been used. The wave period is obtained using the expression recommended by the Spanish Harbour Authority (e.g. Puertos del Estado, 2013):

$$
T_{P}=a H_{s}^{b}
$$

where $T_{p}$ is the peak period and $a, b$ are two coefficients fitted to each wave projection data set.

The wave parameters thus obtained are representative of the wave conditions at the outer boundary of the coarser grid, and have been used as input for the SWAN model. With this data a directional spectrum is defined, which is discretized in 30 frequencies and 36 directions to run the model. The SWAN results provide the boundary conditions for the BT model at the finer grid, which is then run to obtain the values of $\mathrm{H}_{\mathrm{s}}$ at all the grid points within the harbour with a $5 \mathrm{~m}$ resolution.

The wave propagation patterns within the port are very complex because multiple reflections take place, generating waves that are propagated in different directions at every berthing. Therefore, to estimate the operability time an analysis considering the wave height and direction at each point of every berthing (of the order of dozens or even hundreds depending on the berthing area) would be necessary, which is an unaffordable task. For this reason, the analysis is performed with a representative value of $\mathrm{H}_{\mathrm{s}}$ for each simulation obtained from all the $\mathrm{H}_{\mathrm{s}}$ at the 
berthing surface. In order to take into account the possible existence of outliers and considering that the average $\mathrm{H}_{\mathrm{s}}$ would give a too low value, the representative value considered is the 90th percentile value, $\mathrm{H}_{90}$. With respect to wave directions, we assume that waves may arrive from all possible directions, so they could be longitudinal or transversal to the dock. Comparing with the two thresholds given in Table 1 (Puertos del Estado, 2000), a range of variation of the inoperability time is obtained, with a minimum value corresponding to waves longitudinal to the dock (which have a higher threshold) and a maximum given by waves perpendicular to the berths. Nevertheless, for the application of this approach to other ports and for obtaining more accurate results, the longitudinal and transverse components of the wave height should be discriminated. Thereby, inoperability times could be assessed more precisely instead of estimating a range of variation. This would be especially useful for ports whose operability could be greatly affected by climate change.

In summary, to assess the impact of climate change on wave agitation in Barcelona port, the following methodological steps are carried out:

- The wave periods associated to the five representative wave heights $H_{s}[0.5,1.5,2.5,3.5$ and 5] $\mathrm{m}$ are computed using expression (1) for present and future wave conditions. Note that although the $H_{s}$ are the same in both cases, the associated $T_{p}$ may be different for present and future wave conditions, since parameters $a$ and $b$ in (1) are fitted to different series of wave data.

- The 40 wave types representative of each scenario (8 directions $\times 5 \mathrm{H}_{s}$ and $\mathrm{T}_{\mathrm{p}}$ ) are propagated using the SWAN model. For scenarios 0 and 1 , the present bathymetry is used, while for scenarios 2 and 3, the water depth is increased with the SLR considered. The wave conditions given by the SWAN model at the outer limit of the BT model are used as boundary conditions to run this last model and simulate the propagation of waves within the port (at each grid point), for the 4 cases (present conditions and future conditions with 3 scenarios of SLR), obtaining the distribution of $\mathrm{H}_{\mathrm{s}}$ for each scenario and each wave set $\left(\mathrm{H}_{\mathrm{s}}, \mathrm{T}_{\mathrm{p}}\right.$ and direction).

- At each one of the 21 berthing areas (see Fig. 2) the representative value $\mathrm{H}_{90}$ is computed for each simulation from all the $\mathrm{H}_{\mathrm{s}}$ obtained at the berthing surface.

- For each berthing and each simulation, $\mathrm{H}_{90}$ is compared to the corresponding threshold values (see Table 1). If one or both threshold values are exceeded, this berthing becomes inoperative for this particular wave set. Therefore, the berth inoperability time is related to the frequency of occurrence of these specific wave sets.

- The sum of the frequencies of occurrence from all the wave sets exceeding the threshold at every berth gives its total inoperability time, for each one of the 4 studied scenarios. Note that two values of inoperability time are obtained, one for longitudinal waves to the dock and the other for transversal waves, giving the range of variation for this inoperability time at every berthing area.

- Finally, inoperability time results obtained at each berth for the 3 future scenarios are compared with those from the present one, to assess how changes in wave climate and SLR will affect the port operability. 


\section{Results and discussion}

Before analyzing the results of the SWAN and BT models, present and future wave data at point A (Fig. 1) are compared. As indicated in Section 2.2, the time periods used in AR5 (Church et al., 2013) are considered, i.e. 1986-2005 for present conditions and 2081-2100 for future climate. Table 3 and Fig. 5 summarize the wave heights and directions for both periods.

\begin{tabular}{|c|c|c|c|c|c|c|c|c|}
\hline \multirow{2}{*}{$\mathbf{H}_{\mathbf{s}}(\mathrm{m})$} & \multicolumn{9}{|c|}{ Direction } \\
\cline { 2 - 9 } & ENE & $\mathbf{E}$ & ESE & SE & SSE & S & SSW & SW \\
\hline $\mathbf{0 - 1}$ & 17.28 & 11.75 & 10.93 & 12.53 & 5.25 & 7.35 & 14.78 & 3.19 \\
\hline $\mathbf{1 - 2}$ & 0.65 & 1.30 & 1.54 & 0.51 & 0.20 & 0.36 & 2.56 & 0.73 \\
\hline $\mathbf{2 - 3}$ & 0.16 & 0.34 & 0.31 & 0.02 & 0.02 & 0.03 & 0.45 & 0.05 \\
\hline $\mathbf{3 - 4}$ & 0.02 & 0.08 & 0.03 & 0.01 & 0.00 & 0.00 & 0.06 & 0.00 \\
\hline $\mathbf{> 4}$ & 0.00 & 0.03 & 0.04 & 0.00 & 0.00 & 0.00 & 0.02 & 0.00 \\
\hline Total & 18.11 & 13.50 & 12.85 & 13.07 & 5.47 & 7.74 & 17.87 & 3.97 \\
\hline
\end{tabular}

\begin{tabular}{|c|c|c|c|c|c|c|c|c|}
\hline \multirow{2}{*}{$\mathbf{H}_{\mathbf{s}}(\mathrm{m})$} & \multicolumn{9}{|c|}{ Direction } \\
\cline { 2 - 9 } & ENE & $\mathbf{E}$ & ESE & SE & SSE & S & SSW & SW \\
\hline $\mathbf{0 - 1}$ & 18.98 & 12.57 & 13.40 & 14.43 & 4.49 & 5.35 & 11.12 & 2.56 \\
\hline $\mathbf{1 - 2}$ & 0.72 & 1.53 & 1.83 & 0.73 & 0.20 & 0.35 & 2.72 & 0.65 \\
\hline $\mathbf{2 - 3}$ & 0.17 & 0.41 & 0.38 & 0.05 & 0.01 & 0.01 & 0.41 & 0.04 \\
\hline $\mathbf{3 - 4}$ & 0.02 & 0.09 & 0.10 & 0.00 & 0.00 & 0.00 & 0.06 & 0.00 \\
\hline $\mathbf{> 4}$ & 0.00 & 0.02 & 0.04 & 0.00 & 0.00 & 0.00 & 0.01 & 0.00 \\
\hline Total & 19.89 & 14.62 & 15.75 & 15.21 & 4.70 & 5.71 & 14.32 & 3.25 \\
\hline
\end{tabular}

Table 3 Frequencies of occurrence for the defined wave height intervals and wave direction sectors in front of the Barcelona port (point A, Fig. 1) for present (top) and future (bottom) conditions.
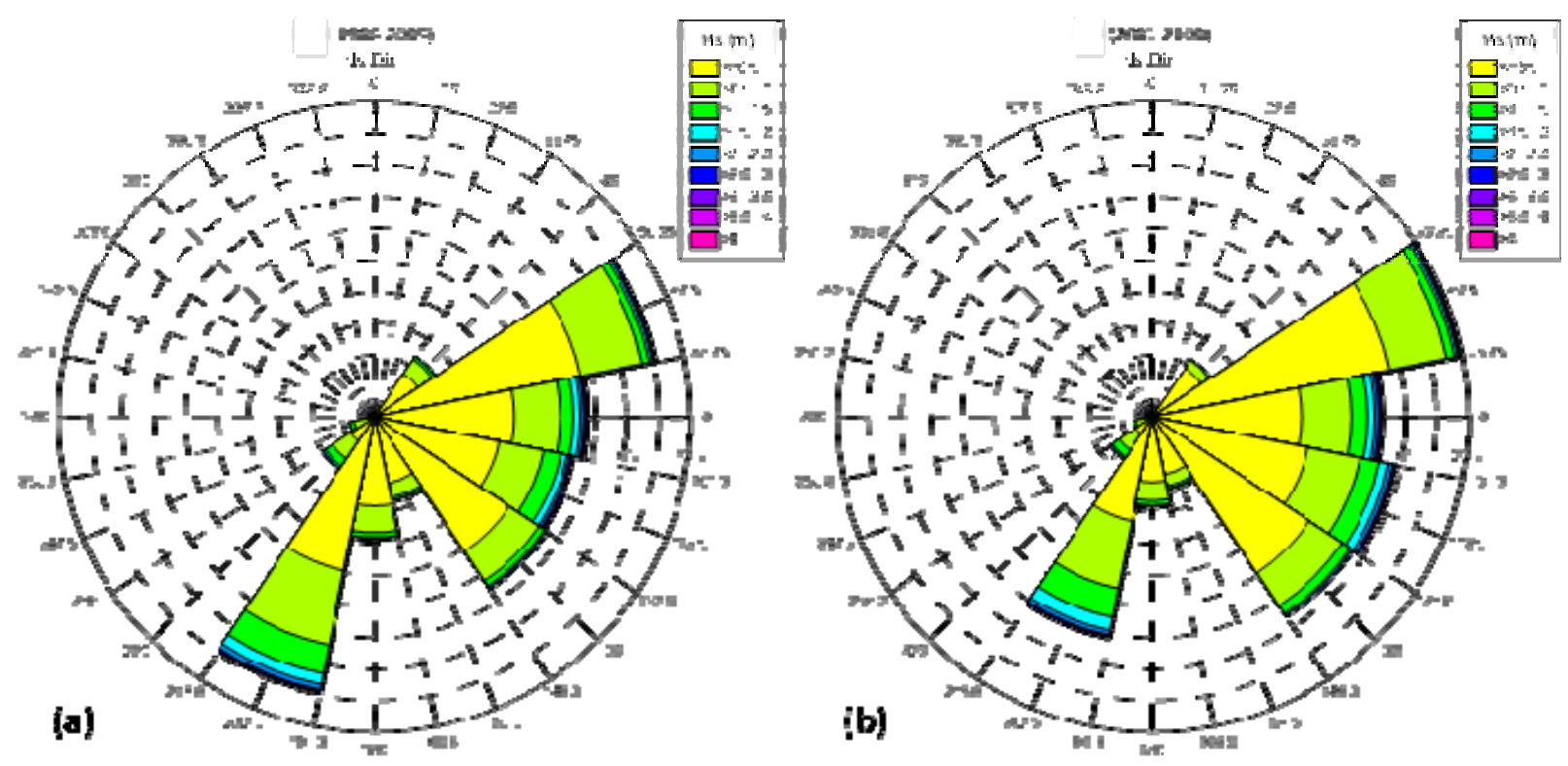

Fig. 5 Wave roses of significant wave height (Hs) and direction (Dir) for: (a) present (1986-2005) and (b) future (20812100) conditions. 
Results shown in Fig. 5 and Table 3 indicate that the frequency of waves coming from directions between ENE and SE will increase in the future, while, on the contrary, it will decrease for waves from the sectors between SSE and SW. Notice that the changes are focused on the lower wave height intervals. In principle, this variation of the directional distribution of waves is positive for Barcelona port, since both port entrances are oriented towards the S and SSW. Therefore, those waves having a more direct incidence on the harbour will be less frequent and the wave agitation within the port will be reduced. Nevertheless, the complex wave propagation patterns associated to an infrastructure like Barcelona port, in which processes such as reflection can produce unexpected effects and direct energy to berthing areas, may introduce changes in these a priori expectations.

These changes in the directional frequency of waves are consistent with those found in the wave data from scenario A1B used in Sierra et al. (2015) for this area, where the occurrence frequency increased for waves from the $E(+1.8 \%$ in the ensemble average with variations between $+0.3 \%$ and $+4.7 \%)$ and from SE $(+1.7 \%$ in average ranging from $+0.4 \%$ to $2.7 \%$ in the different models). On the contrary, in this previous work, decreases in frequency were obtained for waves from the $S(-1.5 \%$ in average, varying between $-3.2 \%$ and $-0.4 \%)$ and from the SW ($0.8 \%$ in average, ranging from $-1.5 \%$ and $+0.5 \%$ ).

Once the frequencies for each direction and range of wave heights have been obtained for present and future conditions, the simulations with the SWAN model have been carried out, for the 4 considered scenarios and the 40 wave conditions ( 8 directions $\times 5$ wave heights/periods). The results of this model were used to feed the BT model. In Figs. 6-9 several randomly selected samples of the simulations with both models are plotted.

Fig. 6 shows an example of the influence of wave direction on the wave patterns obtained with the SWAN model. In this figure, for present conditions and $\mathrm{H}_{\mathrm{s}}=3.5 \mathrm{~m}$, the results given by SWAN for four different directions (ENE, SE, S and SW) are plotted, showing how the wave direction clearly affects the wave field around Barcelona port. Besides shoaling and refraction effects, the impact of the bulge of Llobregat Delta (see Fig. 1) is evident due to the shelter it provides from the most oblique waves (ENE and SW), which are diffracted at the delta and reduce their $\mathrm{H}_{\mathrm{s}}$ significantly.

The impact of changes in future wave fields with respect to the present can be examined in Fig. 7 , where an example of the propagation pattern of the same wave set $\left(\mathrm{H}_{\mathrm{s}}=3.5\right.$ and direction ENE) is plotted for present conditions, together with the differences in $\mathrm{H}_{\mathrm{s}}$ for the three future scenarios. Differences are practically negligible $\left(\Delta \mathrm{H}_{\mathrm{s}}< \pm 0.05 \mathrm{~m}\right)$ in most of the domain, since here the variation of water depth due to SLR only represents a small fraction of the present depth, and because the wave periods are practically the same for present and future conditions. In the shallower nearshore area, larger variations of $\mathrm{H}_{\mathrm{s}}$ can be observed (Fig. 7) when a nonzero SLR is considered. This indicates that the differences among the distinct scenarios will be given by the variations in frequency of each set of waves rather than by modifications in the wave field due to changes in wave periods (which are minimal) or water depths. 


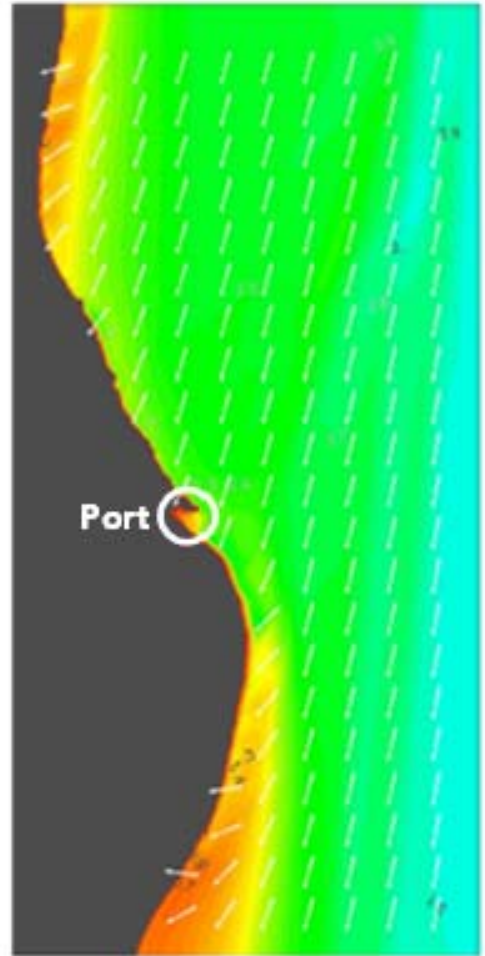

(a) Direction: E-NE

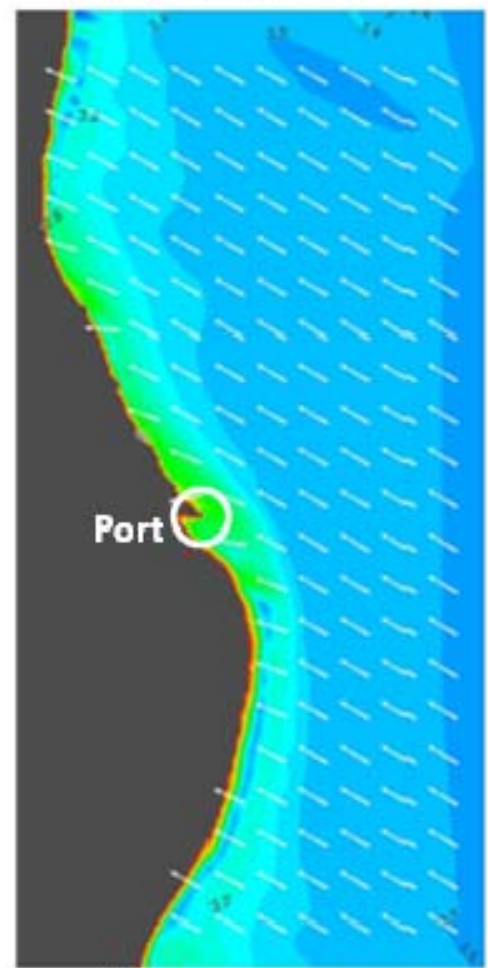

(c) Direction: S

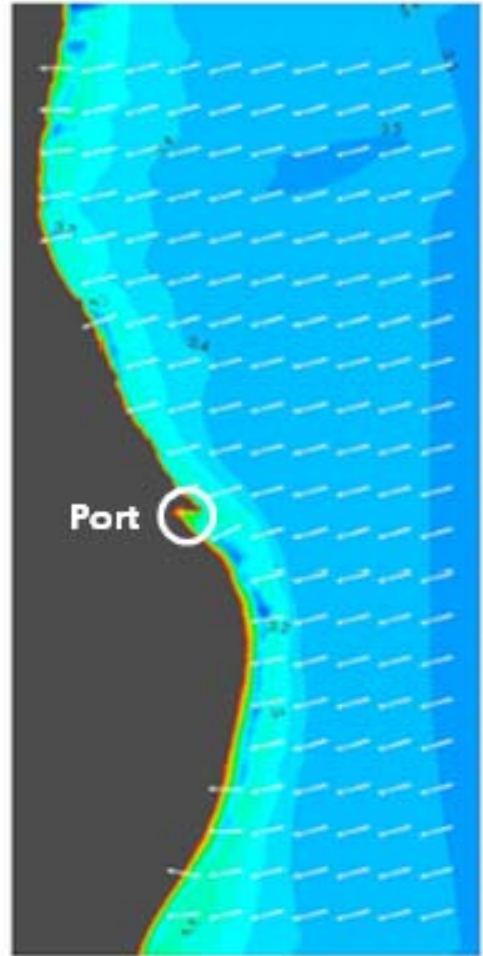

(b) Direction: SE

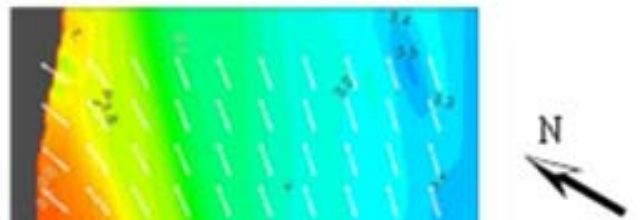

Hs

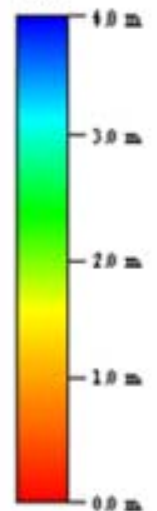

$5 \mathrm{~km}$

Fig. 6 SWAN results for present conditions, $H_{s}=3.5 \mathrm{~m}$ and four different wave directions. 


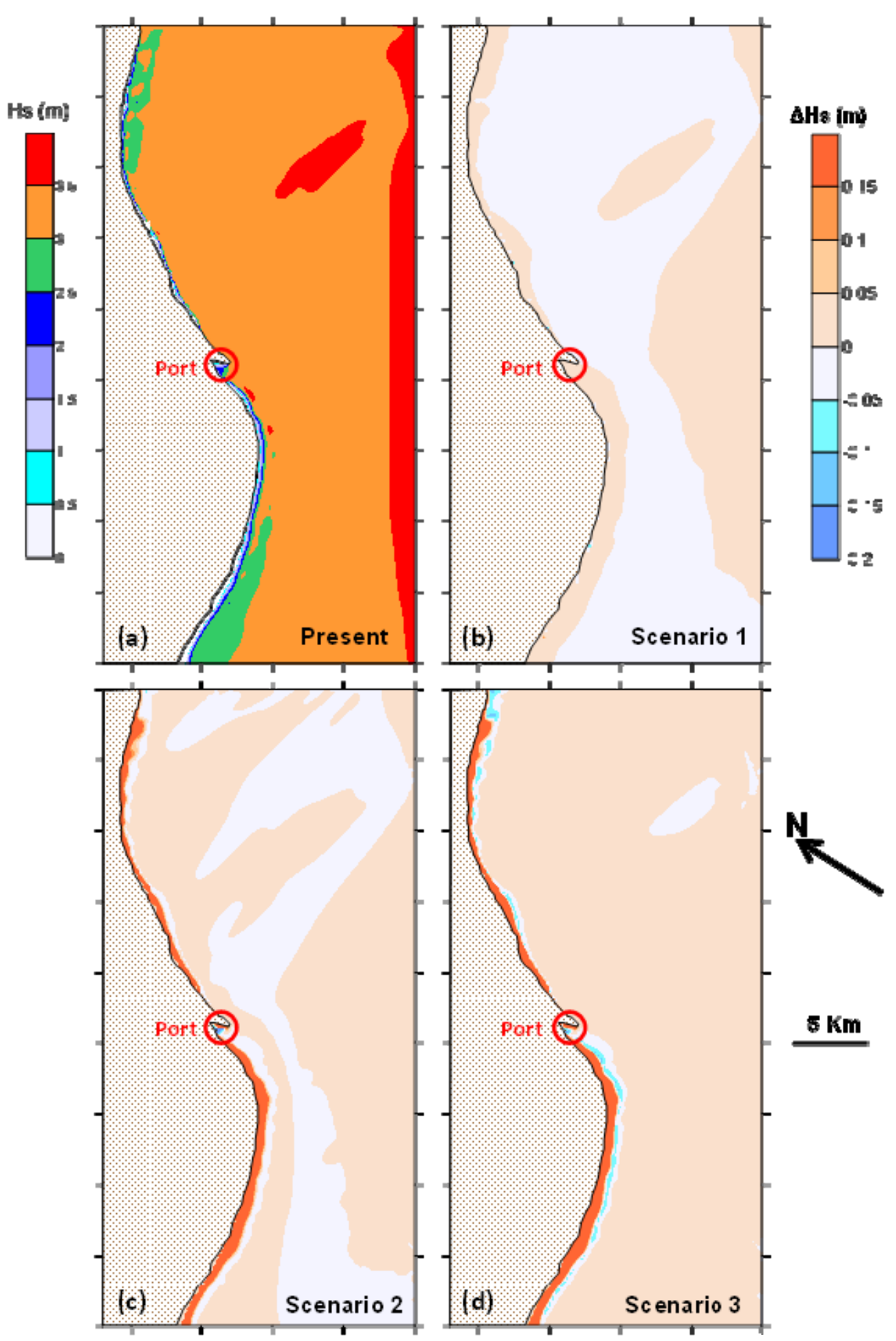

Fig. 7 SWAN results for the four scenarios for waves with $H_{s}=3.5 \mathrm{~m}$ and ESE direction. (a): values of $H_{s}$ given by the model for the present situation.(b), (c) and (d): Differences of $\mathrm{H}_{\mathrm{s}}$ between the three future scenarios and the present conditions. 

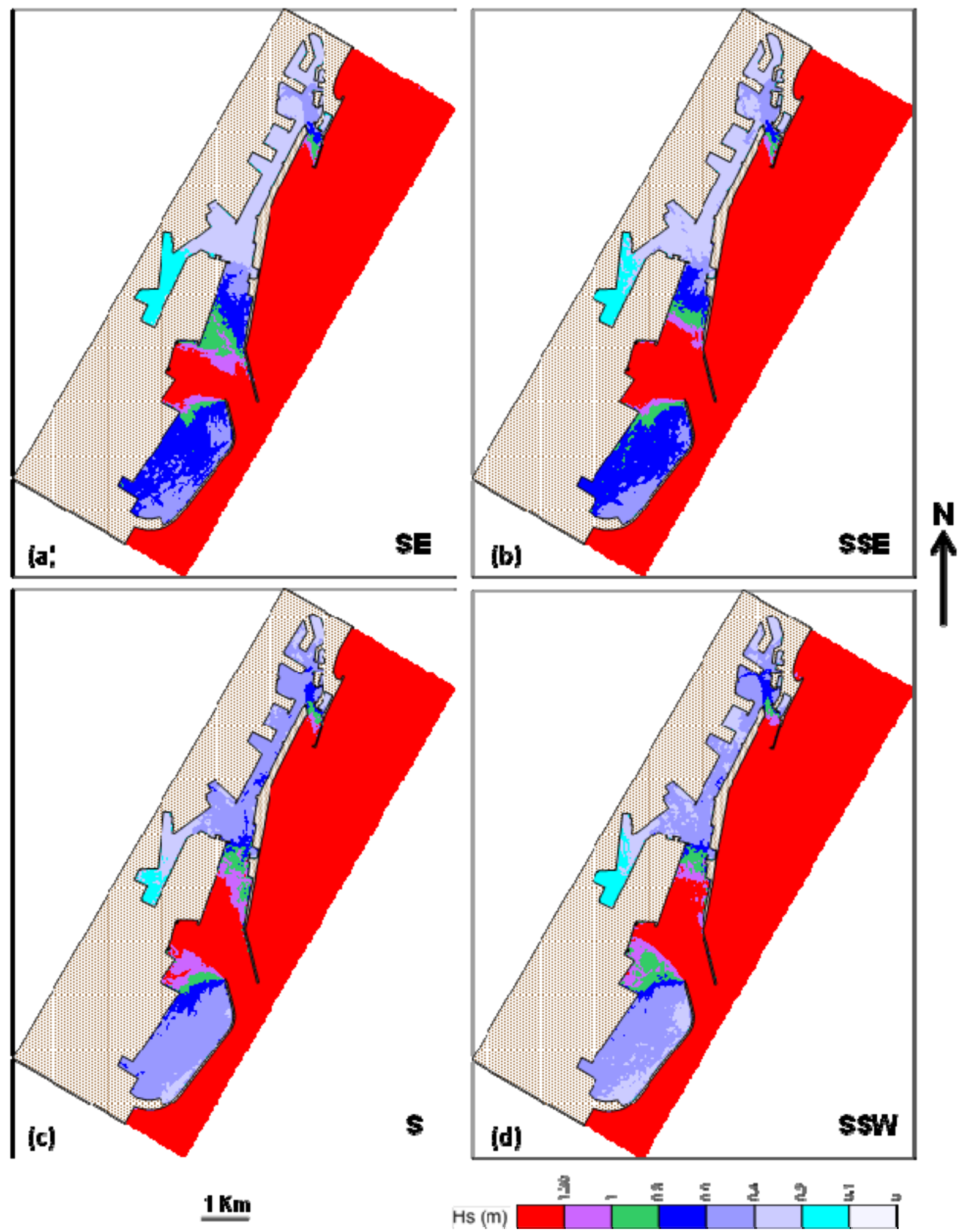

Fig. 8 BT model results for present wave direction conditions, $H_{s}=4.5 \mathrm{~m}$ and four different wave directions. 


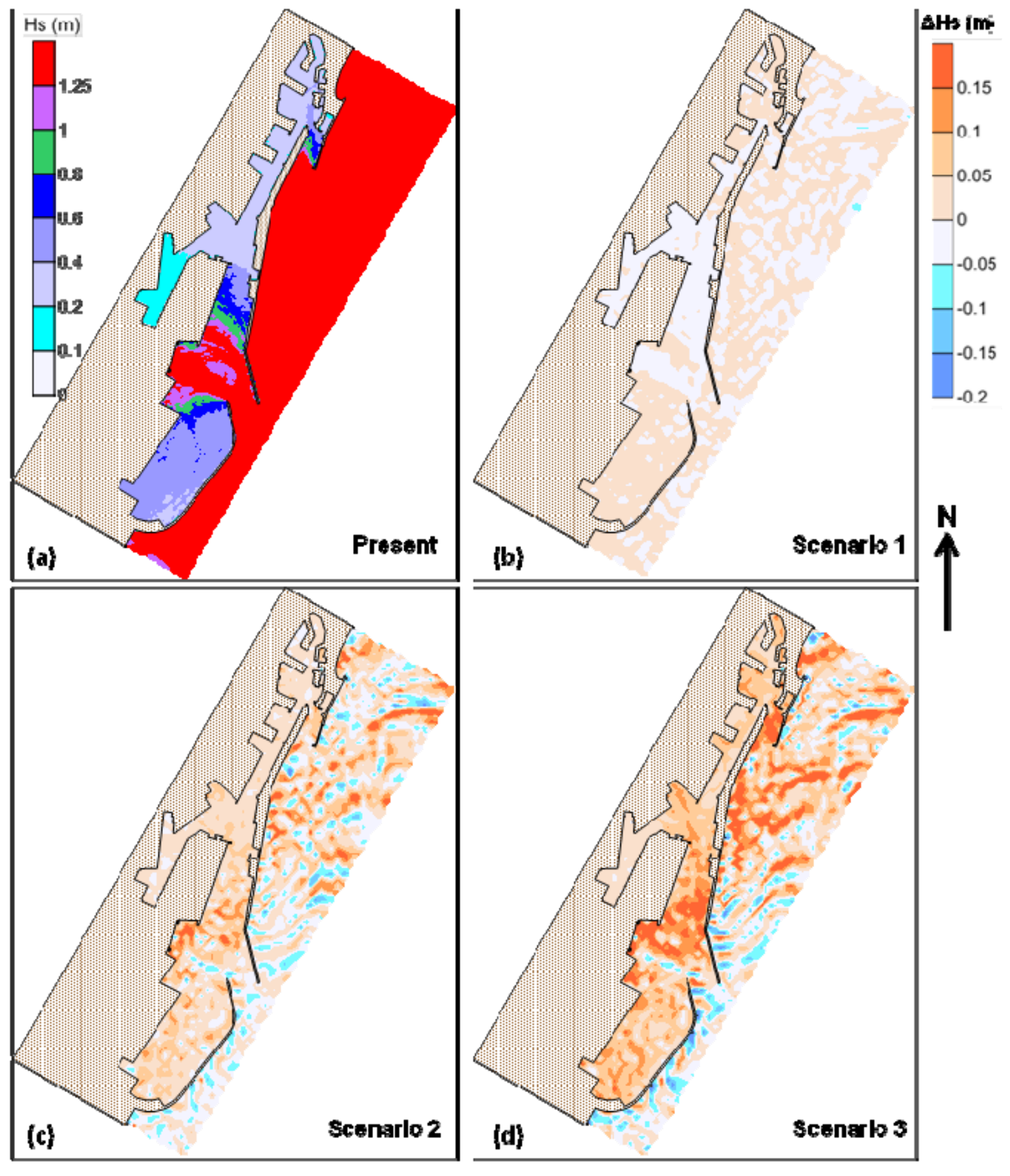

$1 \mathbf{k m}$

Fig. 9 BT model results of wave propagation for the 4 scenarios, with $H_{s}=2.5 \mathrm{~m}$ and SSE direction. (a): values of $\mathrm{H}_{\mathrm{s}}$ given by the model for the present situation. (b), (c) and (d): Differences of $\mathrm{H}_{\mathrm{s}}$ between the three future scenarios and the present conditions.

A similar analysis has been performed for the BT model results. Fig. 8 shows an example (for offshore $\mathrm{H}_{\mathrm{s}}=4.5 \mathrm{~m}$ ) of the influence of wave direction on the wave field within the harbour. In 
this figure, the significant wave heights are plotted for present conditions and four directions, showing how the port structures channel the wave energy depending on their orientation. Thus, since the southern (and larger) port mouth is oriented towards the south, waves with S and SSW directions enter directly into the harbour, funneled by the two parallel breakwaters that form the mouth and generating larger $\mathrm{H}_{\mathrm{s}}$ in all the harbour except in the southernmost basin (number 21 in Fig. 2). On the contrary, waves with an E component (SSE and SE in Fig. 8) diffract at the southern breakwater resulting in more energy penetrating in this southernmost basin.

The northern port mouth is oriented towards the SSW, so waves coming from this direction generate the largest wave energy inflow within the northernmost harbour area. As wave direction turns eastwards, the amount of energy entering through this mouth decreases. This illustrates the importance of wave direction in the distribution of wave energy inside the port and therefore the relationship between wave direction and port operability.

In Fig. 9, an example of the effect of future changing conditions is shown, by comparing the wave propagation under present situation with the three future scenarios considered in this work for the same wave set $\left(\mathrm{H}_{\mathrm{s}}=2.5 \mathrm{~m}\right.$ and SSE direction). Because the wave periods are practically invariant, if SLR is not considered the differences between future and present conditions are practically negligible $\left(\Delta \mathrm{H}_{\mathrm{s}}< \pm 0.05 \mathrm{~m}\right)$ and the distribution of $\mathrm{H}_{\mathrm{s}}$ inside the harbour is practically the same (Fig. 9b).

When the effect of SLR is taken into account, certain differences in the wave field appear. As SLR (and therefore water depth) increases, waves penetrate farther into the harbour and larger values of $H_{s}$ are found therein. This is specially clear in the southernmost basin and the areas closest to both port mouths. Notice that the changes (Fig. 9) are more evident for the BT results than for the SWAN simulations (Fig. 7). The reason is that, in this case, the water depths are smaller $(<20 \mathrm{~m})$ and the two considered SLRs represent a non-negligible change (in \%) in depth. Larger water depths entail longer waves and, therefore, greater diffraction coefficients. As a consequence, $\mathrm{H}_{\mathrm{s}}$ will increase and the dock operability could be reduced.

For every simulation carried out, all the $\mathrm{H}_{\mathrm{s}}$ obtained at each berthing area are stored and the 90th percentile $\left(\mathrm{H}_{90}\right)$ is computed to have a representative value of wave height for that simulation. Fig. 10 shows an example of the $\mathrm{H}_{90}$ obtained at each berth for one wave type $\left(\mathrm{H}_{\mathrm{s}}=\right.$ $2.5 \mathrm{~m}$ and direction SE) and the four studied scenarios.

Results shown in Fig. 10 confirm the previously indicated trends. The differences between the present and future $\mathrm{H}_{\mathrm{s}}$ (without SLR) are negligible, since the wave periods are practically the same and, accordingly, the wave fields within the port are very similar. However, as SLR increases $\mathrm{H}_{90}$ is greater in almost all the basins, due to the increase of the wave length and the diffraction coefficient.

By combining the results like those of Fig. 10 for all the wave sets considered with the frequencies of occurrence of each wave set (Table 3 ) and the threshold wave heights defining dock inoperability (Table 1), the yearly inoperability time of each berthing area for every scenario is obtained. Figs. 11 and 12 show the number of hours during which the loading/unloading 
operations would not be feasible, for each berthing and for the 4 scenarios considered. The two plots indicate the minimum and maximum values of inoperability time, associated respectively to waves parallel or perpendicular to the dock, since in the first case the wave height threshold is greater than in the second one.

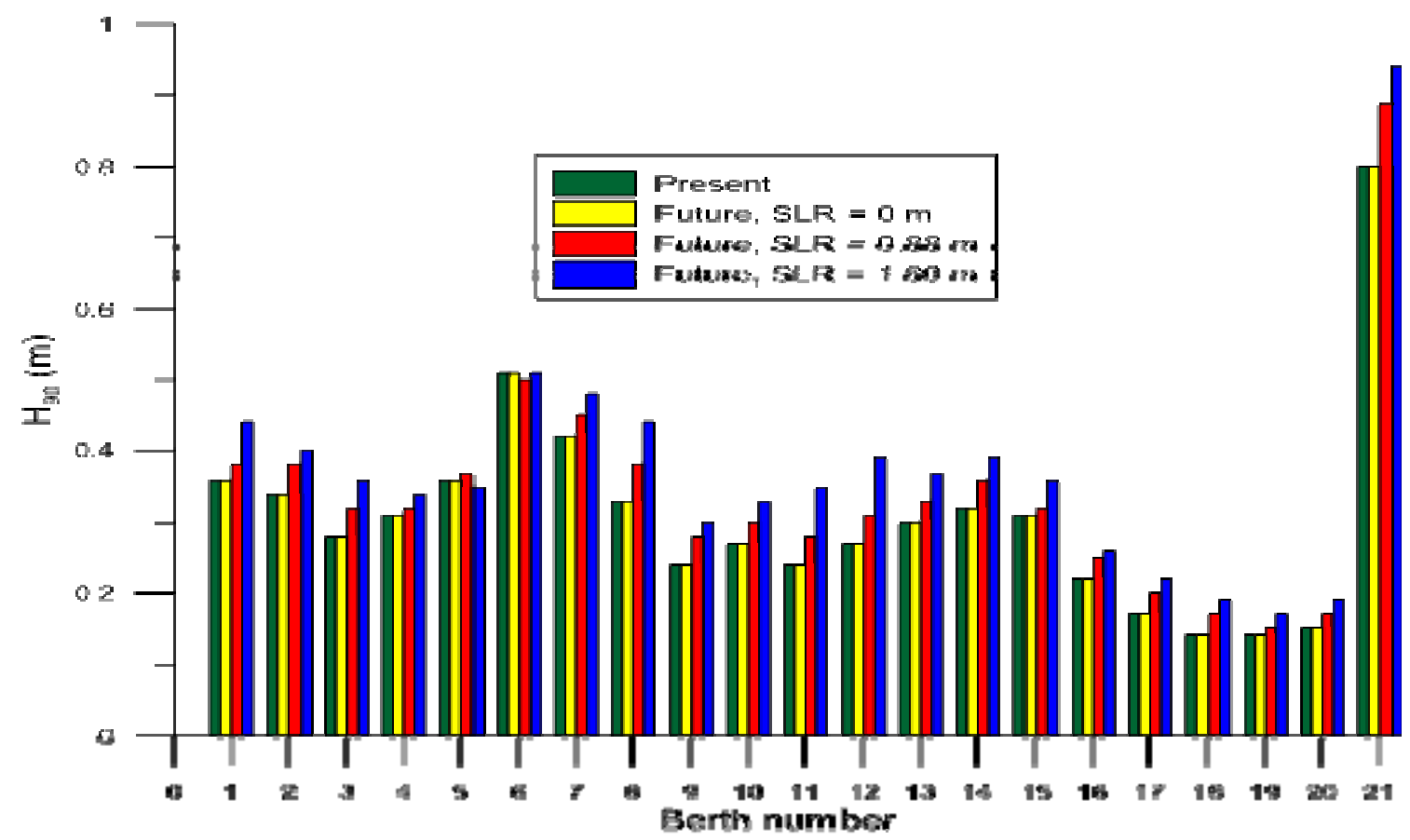

Fig. 10 90th percentile of the significant wave heights recorded at each berth for waves from the SE and initial $H_{s}=$ $2.5 \mathrm{~m}$, for the 4 scenarios analyzed.

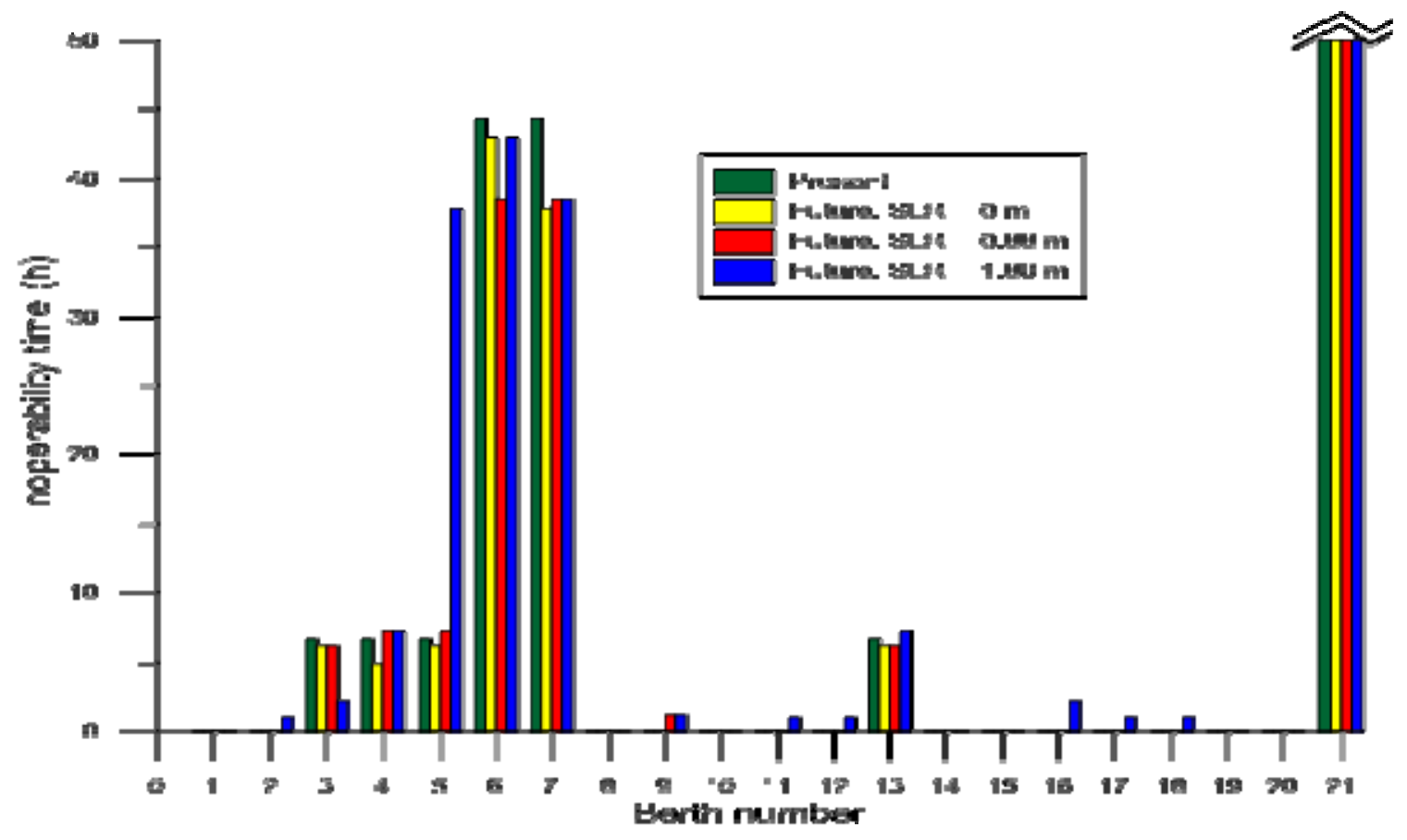


Fig. 11 Minimum yearly inoperability time (in h) at each berthing for the 4 scenarios considered. These values are obtained assuming that waves are parallel to the docks. The vertical axis has been cut at $50 \mathrm{~h}$ to better see the smaller numbers at other berths. In berth 21 the inoperability time is $112.6 \mathrm{~h}$ for present conditions and $137.5 \mathrm{~h}$ for the three future scenarios.

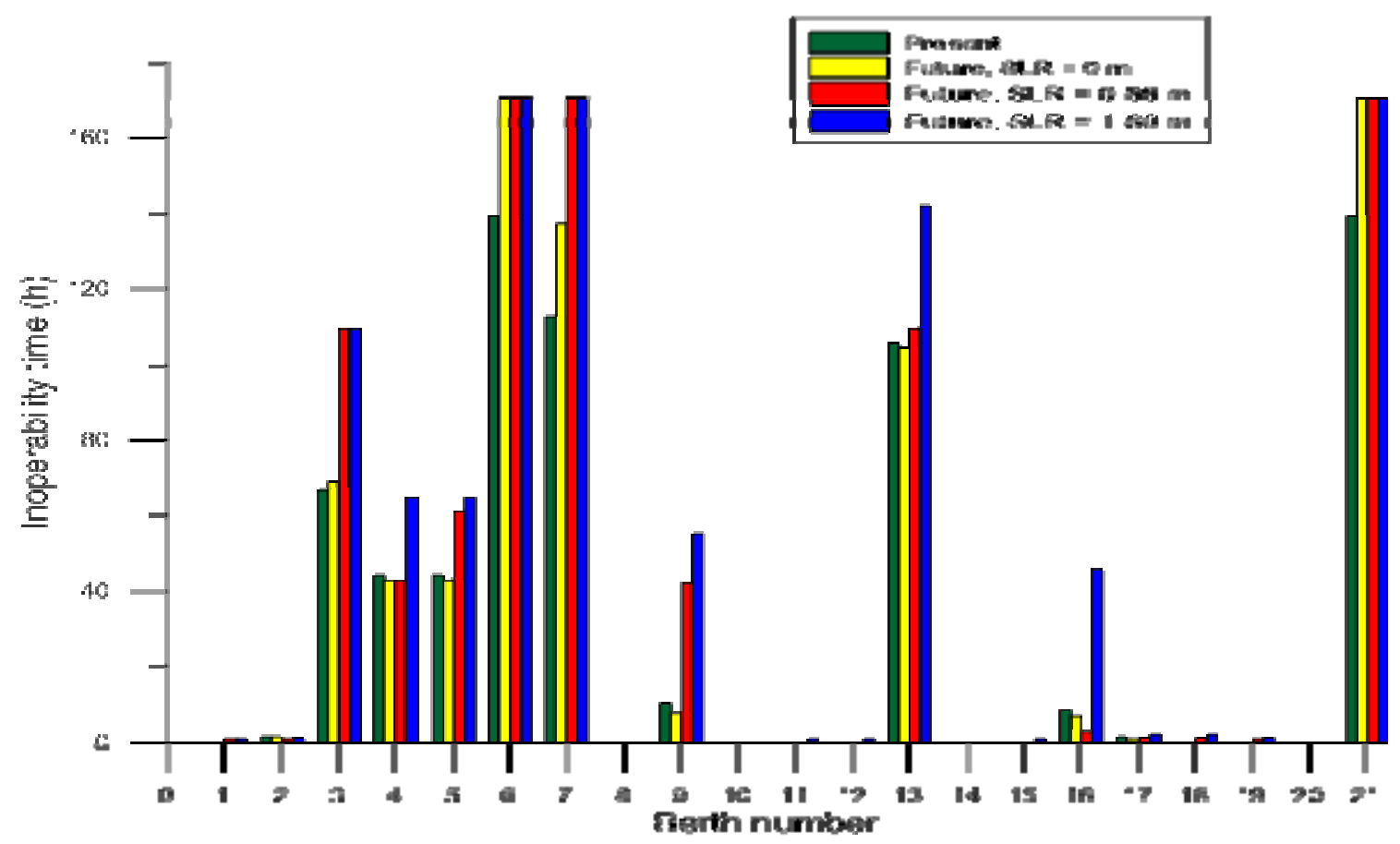

Fig. 12 Maximum yearly inoperability time (in hours) at each berthing for the 4 scenarios considered. These values are obtained assuming that waves are perpendicular to the docks.

It is worth noting from Figs. 11 and 12 that, under present conditions, about half of the docks (10) are operational all the time. In the case of along-dock waves (Fig. 11) only 3 berthing areas present significant inoperability times: berth $6(44.4 \mathrm{~h}$ or $0.5 \%$ of the time), berth $7(41.2 \mathrm{~h}$ or $0.47 \%)$ and berth $21(113 \mathrm{~h}$, or $1.3 \%)$, while the other 18 present less than $7 \mathrm{~h}(0.08 \%)$ of inoperability per year (in 14 of them the value is $0 \mathrm{~h}$ ).

In the case of transversal waves the inoperability is obviously larger, with 10 docks operating all the time, 4 with small inoperability (up to $10.5 \mathrm{~h} /$ year) and the other 7 with greater values (between 44.4 and $139.6 \mathrm{~h} /$ year, or between $0.5 \%$ and $1.6 \%$ of the time). Of the later, berths 6 , 7,13 and 21 exceed $100 \mathrm{~h}(1.1 \%$ of the time) of inoperability per year. These berths are the ones with the lowest thresholds $(0.3 \mathrm{~m}$ for transversal waves), which correspond to cruises, ferries or container terminals.

If scenario 1 is considered (future wave climate without SLR), the obtained results are similar to those of the present situation, with a general trend (with some exceptions) to slightly decrease the inoperability times, as it could be expected due to the reduced frequency of the southerly waves. This slight decrease of future wave agitation is in agreement with the results of Sierra et 
al. (2015) for the AR4 A1B scenario (IPCC, 2007), who also found slight decreases of $H_{s}(-$ $1.09 \%$ averaged over the whole port) from an ensemble of wave data obtained with 5 different combinations of GCM/RCM models. However, the results of Sierra et al. (2015) showed certain range of variability between models $(-4.84 \%$ to $+2.75 \%)$ as well as seasonal variability $(-5.04 \%$ in winter and $+2.74 \%$ in summer in the ensemble average).

In the case of along-dock waves, those docks with present full-time operability remain the same, while the others sustain slight decreases except at berth 21 , where the inoperability time increases from 112.6 to $137.5 \mathrm{~h} /$ year $(1.29 \%$ to $1.57 \%$ of the time). In the case of waves perpendicular to the dock, there is also a trend to maintain the full operability in those areas that are currently $100 \%$ operable, and to slightly decrease the inoperability time in other berths, but there are four docks $(3,6,7$ and 21) where this time increases. In the case of berth 21 , it is explained because waves from the SE (due to the diffraction at the southern breakwater) produce larger $\mathrm{H}_{\mathrm{s}}$, and the frequency of occurrence of waves from this direction is greater for future conditions (see Fig. 5). In the other three berths, there is no clear explanation for this increase of inoperability when waves are transversal to the dock, and only the complexity of the wave field within the harbour, due to multiple reflections between adjacent structures could justify such increases.

In the case of scenario 2 (RCP8.5, the worst scenario projected in the AR5 from IPCC), the general trend is a relatively moderate increase of inoperability with respect to scenario 1 , but with some exceptions in berths that show slight inoperability decreases with respect to present conditions (berths 3, 6, 7 and 13 for longitudinal waves and 4, 16 and 17 for transversal waves). In this case the number of berths operative all-time is 13 and 7 for waves parallel and transversal to the dock, respectively. In summary, scenario 2 presents a slightly worst behavior than scenario 1, in particular in the case of transversal waves for berths 3,5 and 9 .

In the case of the very unlikely scenario 3 (future waves and SLR $=1.80 \mathrm{~m}$ ) the inoperability would increase substantially in almost all the berths. Only 4 docks would be operative all the time considering transversal waves, and 7 considering along-dock waves. In some cases the increase in inoperability time with respect to the present conditions would exceed $400 \%$ (e.g. berth 5 for longitudinal waves and berths 9 and 16 for transversal waves). This large increase would be due to the aforementioned increment of water depths (greater than $10 \%$ in all the berths) leading to larger waves penetrating into the harbour. There are some berths which would not follow the general trend. In this case, berths 3, 6 and 7 would have again an anomalous behavior, with slight decreases of inoperability time for waves parallel to the dock.

Note that these results are obtained assuming that the harbour lay-out will remain unchanged in the next decades, because its future evolution is unknown. Moreover, the future evolution of maritime traffic (type of vessels, equipment, loading/unloading operations and therefore $\mathrm{H}_{\mathrm{s}}$ thresholds) is also unknown and has not been considered in this study. Nevertheless, although the results for future scenarios could differ due to these factors, the observed general trends (slightly decrease of $\mathrm{H}_{s}$ due to changes in wave directions and increase of $\mathrm{H}_{s}$ due to SLR) are likely to be confirmed. In addition, a specific process of calibration of the models in this port is 
necessary. For this reason, wave gauges should be placed at different points within the harbour to gather wave data. The most interesting areas for monitoring the wave climate within the Barcelona port are: both port mouths, berths 5, 13 and 21 and the dock located in front of the main (southern) port mouth.

Finally, it is noteworthy that the recommendations of the Spanish Harbour Authority (Puertos del Estado, 2000) state that, for specialized port terminals, the average acceptable inoperability time due to adverse climatic conditions is $200 \mathrm{~h} / \mathrm{yr}$. Despite the significant increment of inoperability times in several basins due to SLR, even in the worst projected conditions, this limit will not be reached at any berthing in Barcelona port.

\section{Summary and conclusions}

The main objective of this paper is to analyze how the changes in wave patterns and SLR due to climate change may affect wave agitation and, as a consequence, port operability. Though this study is focused on Barcelona port (NW Mediterranean), the used methodology can be applied to any port. Results are based on wave projections obtained with the WAM model in the Mediterranean Sea (at a resolution of $0.25^{\circ} \times 0.25^{\circ}$ ) and considering the RCP8.5 scenario from AR5 of IPCC and three values of SLR.

The wave projections are used to define present (1986-2005) and future (2081-2100) wave climates. Once wave climates are obtained, a representative set of wave parameters is propagated using the SWAN model (at a spatial resolution of $200 \times 200 \mathrm{~m}$ ) from the closest WAM node to the limit of the BT model, which simulates the propagation of waves (at a resolution of $5 \times 5 \mathrm{~m}$ ) inside the harbour, where 21 berthing zones are defined according to their features. By comparing a representative value of $\mathrm{H}_{\mathrm{s}}$ at each berthing area with the operability thresholds established by the Spanish Harbour Authority (Puertos del Estado), a range of inoperability time (from a minimum to a maximum of hours per year) is estimated for 3 plausible future scenarios.

According to wave projections in the area of the Barcelona port, by the end of the 21st century, the frequency of occurrence of waves from SSE to SW will decrease, increasing for those waves from ENE to SE. These changes in wave direction will, in general, benefit the port and slightly increase its operability due to the orientation of the two port mouths (S and SSW).

Regarding the SLR, the increase in water depth leads to longer waves reaching the port, which in turn increases the diffraction coefficient and, as a consequence, $\mathrm{H}_{\mathrm{s}}$ at the berthing areas and their inoperability time. The greater the SLR, the greater this increasing trend. However, the reduction of operability strongly varies according to the position and orientation of the berthing zones. Differences among the various zones can be explained by the complexity of wave fields inside the port and, in particular, to multiple reflections on port structures.

In Barcelona harbour the SLR impact is of limited extent in absolute values, although in relative terms inoperability time may increase more than $400 \%$ in some berthing areas due to the actual low values of this parameter. Nevertheless, the increase of inoperability time does not exceed 
the limit established by the Spanish Port Authority $(200 \mathrm{~h} / \mathrm{yr})$ as the average acceptable inoperability time due to adverse climatic conditions for any of the considered future scenarios. This means that although climate change may affect the wave agitation in the port of Barcelona increasing the inoperability time, even in the worst (and very unlikely) scenario 3 , the port will not exceed the operability thresholds established by the Spanish port recommendations. Therefore, Barcelona port will not need adaptation measures to face this problem.

This limited impact of SLR in Barcelona port is because the future increase of water level represents a small percentage of the water depth inside the port (of the order of $10 \%$ ). However, in small harbours (marinas, fishing ports) where the basin is 5-6 $\mathrm{m}$ deep or even shallower (very frequent in the NW Mediterranean), a SLR of $0.88 \mathrm{~m}$ or $1.80 \mathrm{~m}$ would entail a very significant relative increment of the depth, thus leading to longer waves, larger diffraction coefficients, higher waves and, eventually, larger inoperability times. This is an issue that deserves further investigation.

The complex patterns of wave propagation inside the harbours, which involve many processes (shoaling, refraction, diffraction, reflection, wave-wave interaction and bottom friction), generate "atypical behaviours" in some basins, which may behave differently from the Barcelona port general trends. This suggests that for studying the potential impacts of climate change in ports a case by case study is necessary, not only at port but also at basin level.

\section{Acknowledgements}

The work described in this publication was funded by the European Union's Seventh Framework Programme through the grant to the budget of the Collaborative Project RISES-AM-, Contract FP7-ENV-2013-two-stage-603396. The authors also wish to acknowledge the financial support and data provided by Puertos del Estado and the Port Authority of Barcelona, via a collaboration agreement. The support of the Secretaria d'Universitats i Recerca del Departament d'Economia i Coneixement de la Generalitat de Catalunya (Ref 2014SGR1253) is also acknowledged.

\section{References}

Abbott, M.B., Petersen, H.M., Skovgaard, O., 1978. On the numerical modelling of short waves in shallow water, J. Hydraul. Res. 6, 173-204.

Adams, P.N., Inman, D.L., Lovering, J.L., 2011. Effects of climate change and wave direction on longshore sediment transport patterns in Southern California. Clim. Change 109, 211-228.

Asariotis, R., Benamara, H. (eds.), 2012. Maritime transport and the climate change challenge. Earthscan/Routledge, New York, NY.

Barnard, P.L., van Ormondt, M., Erikson, L.H., Eshleman, J., Hapke, C., Ruggiero, P., Adams, P.N., Foxgrover, A.C., 2014. Development of the Coastal Storm Modeling System (CoSMoS) for predicting the impact of storms on high-energy, active- margin coasts. Nat. Hazards 74, 1095-1125. 
Becker, A., Acciaro, M., Asariotis, R., Cabrera, E., Cretegny, L., Crist, P., Esteban, M., Mather, A., Messner, S., Naruse, S., Ng, A.K.Y., Rahmstorf, S., Savonis, M., Song, D.-W., Stenek, V., Velegrakis, A.F., 2013. A challenge for global ports, a challenge for global society. Clim. Change 120, 683-695.

Becker, A., Inoue, S., Fischer, M., Schwegler, B., 2012. Climate change impacts on international seaports: knowledge, perceptions, and planning, efforts among port administrations. Clim. Change 110, 5-29.

Becker, A.H., Matson, P., Fischer, M., Mastrandrea, M.D., 2015. Towards seaport resilience for climate change adaptation: Stakeholder perceptions of hurricane impacts in Gulfport (MS) and Providence (RI). Prog. Plan. 99, 1-49.

Belloti, G., 2007. Transient response of harbours to long waves under resonance conditions. Coast. Eng. 54, 680-693.

Belloti, G., Franco, L., 2011. Measurement of long waves at the harbor of Marina de Carrara, Italy. Ocean Dyn. 61, 2051-2059.

Booij, N., Ris, R.C., Holthuijsen, L.H., 1999. A third-generation wave model for coastal regions: 1. Model description and validation. J. Geophys. Res. 104, 7649-7666.

BPA, 2015. Annual report 2014. Barcelona Port Authority, Barcelona, Spain.

Burcharth, H.F., Andersen, T.L., Lara, J.L., 2014. Upgrade of coastal defence structures against increased loadings caused by climate change: a first methodological approach. Coast. Eng. 87, 112-121.

Campins, J., Genovés, A., Picornell, M.A., Jansà, A., 2011. Climatology of Mediterranean cyclones using the ERA-40 dataset. Int. J. Climatol. 31, 1596-1614.

Casas-Prat, M., McInnes, K.L., Hemer, M.A., Sierra, J.P., 2016. Future wave-driven coastal sediment transport along the Catalan coast (NW Mediterranean). Reg. Environ. Change 16, 1739-1750.

Casas-Prat, M., Sierra, J.P., 2010. Trend analysis of wave storminess: wave direction and its impact on harbour agitation. Nat. Hazard Earth Syst. Sci. 10, 2327-2340.

Casas-Prat, M., Sierra, J.P., 2012. Trend analysis of wave direction and associated impacts on the Catalan Coast. Clim. Change 115, 667-691.

Casas-Prat, M., Sierra, J.P., 2013. Projected future wave climate in the NW Mediterranean Sea. J. Geophys. Res. Oceans 118, 3548-3568.

Casas-Prat, M., Wang, X.L., Sierra, J.P., 2014. A physical-based statistical method for modeling ocean wave heights. Ocean Modell. 73, 59-75.

Chhetri, P., Cocoran, J., Gekara, V., Corbitt, B., Wickramasinghe, N., Jayatileke, G., Basic, F., Scott, H., Manzoni, A., Maddox, C., 2013. Functional resilience of port environs in a changing climate - Assets and operations. Work Package 2 of Enhancing the resilience of seaports to a changing climate report series, National Climate Change Adaptation Research Facility, Gold Coast, $118 \mathrm{pp}$.

Chhetri, P., Cocoran, J., Gekara, V., Maddox, C., McEvoy, D., 2015. Seaport resilience to climate change: mapping vulnerability to sea-level rise. J. Spat. Sci. 60, 65-78.

Church, J.A., Clark, P.U., Cazenave, A., Gregory, J.M., Jevrejeva, S., Levermann, A., Merrifield, M.A., Milne, G.A., Nerem, R.S., 2013. Sea level change. In: Stocker, T.F., Qin, D., Plattner, G.-K., Tignor, M., Allen, S.K., Boschung, J., Nauels, A., Xia, Y., Bex, V., Midgley, P.M. (eds.) Climate change 2013: the physical science basis. Contribution of working Group I to the fifth 
assessment report of the intergovernmental panel on climate change. Cambridge University Press, Cambridge, New York NY.

Filippini, A.G., Bellec, S., Colin, M., Ricchiuto, M., 2015. On the non-linear behavior of Boussinesq type models: Amplitude-velocity vs amplitude-flux forms, Coast. Eng. 99, 109123.

Gierlevsen, T., Hebsgaard, M., Kirkegaard, J., 2001. Wave disturbance modelling in the Port of Sines, Portugal - with special emphasis on long period oscillations. Proceedings of the International Conference on Port and Maritime R\&D and Technology, Singapore.

González-Marco, D., Sierra, J.P., Fernández de Ybarra, O., Sánchez-Arcilla, A., 2008. Implications of long waves in harbour management: The Gijon port case study. Ocean Coast. Manag. 51, 180-201.

Grabemann, I., Groll, N., Möller, J., Weisse, R., 2015. Climate change impact on North Sea wave conditions: a consistent analysis of ten projections. Ocean Dyn. 65, 255-267.

Hallegatte, S., Ranger, N., Mestre, O., Dumas, P., Corfee-Morlot, J., Herweijer, C., Wood, R.M., 2011. Assessing climate change impacts, sea level rise and storm surge risk in port cities: a case study on Copenhagen. Clim. Change 104, 113-137.

Hanson, S., Nicholls, R., Ranger, N., Hallegate, S., Corfee-Morlot, J., Herweijer, C., Chateau, J., 2011. A global ranking of port cities with high exposure to climate extremes. Clim. Change 104, 89-111.

Hemer, M.A., Church, J.A., Hunter, J.R., 2010. Variability and trends in the directional wave climate of the Southern Hemisphere. Int. J. Climatol. 30, 475-491.

Hemer, M.A., Fan, Y., Mori, N., Semedo, A., Wang, X.L., 2013b. Projected change in wave climate from a multi-model ensemble. Nat. Clim. Change 3, 471-476.

Hemer, M.A., Katzfey, J., Trenham, C., 2013a. Global dynamical projections of surface ocean wave climate for a future high greenhouse gas emission scenario. Ocean Modell. 70, 221245.

Hemer, M.A., Trenham, C., 2016. Evaluation of a CMIP5 derived dynamical global wind wave climate model ensemble. Ocean Modell. 103, 190-223.

IPCC, 2007. Climate change 2007. The physical science basis. In: Solomon, S., Qin, D., Manning, M. (eds). Contribution of working group I to the fourth assessment report of the Intergovernmental Panel on Climate Change.

Isobe, M., 2013. Impact of global warming on coastal structures in shallow water. Ocean Eng. $71,51-57$.

Jevrejeva, S., Grinsted, A., Moore, J.C., 2014. Upper limit for sea level projections by 2100. Environ. Res. Lett. 9, 104008, doi:10.1088/1748-9326/9/10/104008.

Jevrejeva, S., Moore, J.C., Grinsted, A., 2012. Sea level projections to AD2500 with a new generation of climate change scenarios. Glob. Planet. Change 80-81, 14-20.

Johnson, D., McComb, P., 2011. Modelling long wave generation and propagation around and within ports. Proceedings of Coast and Ports 2011, Perth, Australia, pp. 370-375.

Kane, H.H., Fletcher, C.H., Frazer, L.N., Barbee, M.M., 2015. Critical elevation levels for flooding due to sea-level rise in Hawaii. Reg. Environ. Change 15, 1679-1687.

Karambas, T.W., Koutitas, C., 2004 Resonant response of harbours to short-wave group. Marit. Eng. 157, 163-170. 
Kofoed-Hansen, H., Kerper, D.R., Sørensen O.R., Kirkegaard, J., 2005. Simulation of long wave agitation in ports and harbours using a time-domain Boussinesq model. Proceedings of $5^{\text {th }}$ International Symposium on Ocean Wave Measurement and Analysis - WAVES 2005, Madrid, Spain.

Laugel, A., Menendez, M., Benoit, M., Mattarolo, G., Méndez, F., 2014. Wave climate projections along the French coastline: dynamical versus statistical downscaling methods. Ocean Modell. 84, 35-50.

Lee, C.-E., Kim, S.-W., Park, D.-H., Suh, K.-D., 2013. Risk assessment of wave run-up height and armor stability of inclined coastal structures subject to long-term sea level rise. Ocean Eng. 71, 130-136.

Lionello, P., Cogo, S., Galati, M.B., Sanna, A., 2008. The Mediterranean surface wave climate inferred rom future scenario simulations. Glob. Planet. Change 63,152-162.

Lionello, P., Conte, D., Marzo, L., Scarascia, L., 2016. The contrasting effect of increasing mean sea level and decreasing storminess on the maximum water level during storms along the coast of the Mediterranean Sea in the mid 21st century. Glob. Planet. Change, doi:10.1016/j.gloplacha.2016.06.012.

Lionello, P., Dalan, F., Elvini, E., 2002. Cyclones in the Mediterranean region: the present and the doubled CO2 climate scenarios. Clim. Res. 22, 147-159.

López, I., López, M., Iglesias, G., 2015. Artificial neural networks applied to port operability assessment. Ocean Eng. 109, 298-308.

Martínez-Asensio, A., Marcos, M., Tsimplis, M.N., Jordà, G., Feng, X., Gomis, D., 2016. On the ability of statistical wind-wave models to capture the variability and long-term trends of the North Atlantic winter wave climate. Ocean Modell. 103, 177-189.

Mase, H., Tsujio, D., Yasuda, T., Mori, N., 2013. Stability analysis of composite breakwater with wave-dissipating blocks considering increase in sea levels, surges and waves due to climate change. Ocean Eng. 71, 58-65.

McEvoy, D., Mullett, J., Millin, S., Scott, H. \& Trundle, A., 2013. Understanding future risks to ports in Australia. Work Package 1 of Enhancing the resilience of seaports to a changing climate report series, National Climate Change Adaptation Research Facility, Gold Coast, 77 pp.

Messner, S., Moran, L., Reub, G., Campbell, J., 2013. Climate change and sea level rise impacts at ports and a consistent methodology to evaluate vulnerability and risk. WIT Transactions on Ecology and the Environment 169, 141-153.

Monioudi, I.N., Karditsa, A., Chatzipavlis, A., Alexandrakis, G., Andreadis, O.P., Velegrakis, A.F., Poulos, S.E., Ghionis, G., Petrakis, S., Sifnioti, D., Hasiotis, T., Lipakis, M., Kampanis, N., Karambas, T., Marinos, E., 2016. Assessment of vulnerability of the eastern Cretan beaches (Greece) to sea level rise. Reg Environ Change 16, 1952-1962.

Mori, N., Shimura, T., Yasuda, T., Mase, H., 2013. Multi-model climate projections of ocean surface variables under different climate scenarios: future change of waves, sea level and wind. Ocean Eng. 71, 122-129.

Nicholls, R.J., Marinova, N., Lowe, J.A., Brown, S., Gusmão, D., Hinkel, J., Tol, R.S.J., 2011. Sea-level rise and its possible impacts given a 'beyond $4^{\circ} \mathrm{C}$ world' in the twenty-first century. Philos. Trans. R. Soc. A-Math. Phys. Eng. Sci 369, 161-181. 
Ng, A.K.Y., Chen, S.-L., Cahoon, S., Brooks, B., Yang, Z., 2013. Climate change and the adaptation strategies of ports: The Australian experiences. Res. Transport. Bus. Manag. 8, 186-194.

Nursey-Bray, M., Blackwell, B., Brooks, B., Campbell, M.L., Goldsworthy, L., Pateman, H., Rodrigues, I., Roome, M., Wright, J.T., Francis, J., Hewitt, C.L., 2013. Vulnerabilities and adaptation of ports to climate change. J. Environ. Plan. Manag.

Paudel, Y., Botzen, W.J.W., Aerts, J.C.J.H., 2015. Influence of climate change and socioeconomic development on catastrophe insurance: a case study of flood risk scenarios in the Netherlands. Reg. Environ. Change 15, 1717-1729.

Perez, J., Menendez, M., Camus, P., Mendez, F.J., Losada, I.J., 2015. Statistical multi-model climate projections of Surface ocean waves in Europe. Ocean Modell. 96, 161-170.

PIANC, 2012. Waterborne transport, ports and waterways: A review of climate change drivers, impacts, responses and mitigation. Report of PIANC EnviCom Task Group 3, 57 p.

Puertos del Estado, 2000. ROM 3.1-99. Design of the maritime configuration of ports, approach channels and harbour basins. Recommendations for maritime works Series 3, Puertos del Estado, Madrid, 327p.

Puertos del Estado, 2013. Extremos máximos de oleaje (altura significante): Boya de Barcelona, Banco de Datos Oceanográficos de Puertos del Estado, Madrid, 9p.

Rahmstorf, S., 2007. A semi-empirical approach to projecting future sea-level rise. Science 315, 368-370.

Revell, D.L., Battalio, R., Spear, B., Ruggiero, P., Vandever, J., 2011. A methodology for predicting future coastal hazards due to sea level rise on the California Coast. Clim. Change 109, 251-276.

Reynolds, M.H., Berkowits, P., Coutrot, K.N., Krause, C.M. (eds.), 2012. Predicting sea-level rise vulnerability of terrestrial habit and wildlife of the Northwestern Hawaiian Islands. U.S. Geological Survey Open-File Report 2012-1182.

Rusu, E., Guedes Soares, C., 2011. Wave modelling at the entrance of ports. Ocean Eng. 38, 2089-2109.

Rusu, L., Guedes Soares, C., 2013. Evaluation of a high-resolution wave forecasting system for the approaches to ports. Ocean Eng. 58, 224-238.

Sánchez-Arcilla, A., González-Marco, D., Bolaños, R., 2008. A review of wave climate and prediction along the Spanish Mediterranean coast. Nat. Hazards Earth. Syst. Sci. 8, 12171228.

Sánchez-Arcilla, A., Mösso, C., Sierra, J.P., Mestres, M., Harzallah, A., Senouci, M., El Raey, M., 2011. Climate drivers of potential hazards in Mediterranean coasts. Reg. Environ. Change 11, 617-636.

Sánchez-Arcilla, A., Sierra, J.P., Brown, S., Casas-Prat, M., Nicholls, R.J., Lionello, P., Conte, D., 2016. A review of potential physical impacts on harbours in the Mediterranean Sea under climate change. Reg. Environ. Change 16, 2471-2484.

Sierra, J.P., Casanovas, I., Mösso, C., Mestres, M., Sánchez-Arcilla, A., 2016. Vulnerability of Catalan (NW Mediterranean) ports to wave overtopping due to different scenarios of sea level rise. Reg. Environ. Change 16, 1457-1468.

Sierra, J.P., Casas-Prat, M., 2014. Analysis of potential impacts on coastal areas due to changes in wave conditions. Clim. Change 124, 861-876. 
Sierra, J.P., Casas-Prat, M., Virgili, M., Mösso, C., Sánchez-Arcilla, A., 2015. Impacts on wavedriven harbour agitation due to climate change in Catalan ports. Nat. Hazard Earth Syst. Sci. 15, 1695-1709.

Suh, K.-D., Kim, S.-W., Kim, S., Cheon, S., 2013. Effects of climate change on stability of caisson breakwaters in different water depths. Ocean Eng. 71, 103-112.

Takagi, H., Kashihara, H., Esteban, M., Shibayama, T., 2011. Assessment of future stability of breakwaters under climate change. Coast. Eng. J. 53, 21-39.

The WAMDI Group, 1988. The WAM Model - A third generation ocean wave prediction model. J. Phys. Oceanogr. 18, 1775-1810.

Thotagamuwage, D.T., Pattiaratchi, C.B., 2014. Influence of offshore topography on infragravity period odcillations in Two Rocks Marina, Western Australia. Coast. Eng. 91, 220-230.

Wang, X.L., Feng, Y., Swail, V.R., 2012. North Atlantic wave height trends as reconstructed from the twentieth century reanalysis. Geophys. Res. Lett., 39, L18705, doi:10.1029/2012GL053381.

Wang, X.L., Feng, Y., Swail, V.R., 2014. Changes in global ocean wave heights as projected using multimodel CMIP5 simulations. Geophys. Res. Lett. 41, 1026-1034.

Wang, X., Swail, V., Zwiers, F., Zhang, X., Feng, Y., 2009. Detection of external influence on trends of atmospheric storminess and northern oceans wave heights, Clim. Dynam. 32, 189-203.

Weisse, R., von Storch, H., 2010. Marine climate and climate change. Storms, wind waves and storm surges, Springer Praxis Publishing, Chichester, UK.

Woo, S.-B., Liu, P.L.-F., 2004. Finite-element model for modified Boussinesq equations. II: applications to nonlinear harbor oscillations. J. Waterw. Port Coast Ocean Eng. 130, 1-17.

Zacharioudaki, A., Reeve, D.E., 2011. Shoreline evolution under climate change wave scenarios. Clim. Change 108, 73-105. 